HID 45 (2018)

\title{
¿UN MARCO DE RELACIONES COOPERATIVAS? RELACIONES ECONÓMICAS ENTRE BURGOS, CAPUT CASTELLAE, Y LA CASA DE VELASCO A FINALES DE LA EDAD MEDIA
}

\author{
FRAMING COOPERATIVE RELATIONS? ECONOMIC RELATIONS \\ BETWEEN BURGOS, CAPUT CASTELLAE, AND THE HOUSE OF \\ VELASCO AT THE END OF THE MIDDLE AGES.
}

\author{
Alicia InÉs Montero MÁlaga \\ Universidad Autónoma de Madrid \\ alicia.montero@uam.es ORCID: https://orcid.org/0000-0003-3063-3696
}

RESUMEN: Se examina la participación de la casa de Velasco, condes de Haro (1430), condestables de Castilla (1473) y duques de Frías (1492), en la economía de Burgos, Caput Castellae, a finales de la Edad Media en torno a dos ámbitos. Por un lado, en relación con la fiscalidad regia. En concreto, con la percepción de los privilegios que los titulares del linaje tenían situados en las alcabalas de Burgos, así como con el arrendamiento de estas rentas. Por otro, atendiendo a la intervención de los titulares del linaje en distintas áreas del mercado burgalés. En primer lugar, a través del abastecimiento de productos a la ciudad, en particular de cereal y vino. En segundo lugar, negociando con la ciudad y con la corona exenciones fiscales para la compraventa de productos en la ciudad. Y, finalmente, cooperando con los mercaderes y hombres de negocios burgaleses en el territorio vizcaíno para el aprovechamiento conjunto de los flujos comerciales de la Ría del Nervión.

PAlabras ClaVE: Ciudad; nobleza; fiscalidad; mercado; Burgos; Velasco.

Recibido: 29-1-2018; Aceptado: 24-5-2018; Versión definitiva: 25-6-2018.

1. Abreviaturas utilizadas: $\mathrm{ADPBU}=$ Archivo de la Diputación Provincial de Burgos; AGS = Archivo General de Simancas; AHN = Archivo Histórico Nacional; AHNOB = Archivo Histórico de la Nobleza; AMB = Archivo Municipal de Burgos; AMV = Archivo Municipal de Vitoria; ARChVa = Archivo de la Real Chancillería de Valladolid; $\mathrm{CCA}=$ Cámara de Castilla; $\mathrm{CM}=$ Consulado del Mar; $\mathrm{CMC}=$ Contaduría Mayor de Cuentas $\mathrm{CRC}=$ Consejo Real de Castilla; HI = Sección Histórica; LLAA $=$ Libros de Actas; RGS $=$ Registro General del Sello.

Beneficiaria de un contrato postdoctoral a cargo de la Consejería de Educación, Juventud y Deporte de la Comunidad de Madrid y del Fondo Social Europeo (ref. PEJD-2017-POST/HUM-3886). Este trabajo se ha realizado en el marco del proyecto de investigación Ciudad y nobleza en el tránsito a la Modernidad: autoritarismo regio, pactismo y conflictividad política. Castilla, de Isabel I a las Comunidades (ref. HAR2017-83542-P, Ministerio de Economía, Industria y Competitividad/Agencia Estatal de Investigación/Fondo Europeo de Desarrollo Regional).

Copyright: (C) Editorial Universidad de Sevilla. Este es un artículo de acceso abierto distribuido bajo los términos de la licencia de uso y distribución Creative Commons Reconocimiento-No-ComercialSinObraDerivada 4.0 (CC BY-NC-ND 4.0) 
ABSTRACT: This paper analyses the participation of the house of Velasco, Counts of Haro (1430), High Constables of Castile (1473) and Dukes of Frías (1492) in the economy of the Caput Castellae at the end of the Middle Ages around two main areas. On the one hand, in relation to royal taxation. Specifically, with the perception of the privileges that the title-bearers of the lineage had located in the "alcabala" tax of Burgos, as well as with the farming of these rents. On the other, attending to the intervention of the title-bearers of the lineage in different areas of the Burgos market. First, through the supply of products to the city, in particular cereal and wine. In second place, negotiating with the city and with the crown tax exemptions for the sale of products in the city. And, finally, cooperating with Burgos merchants and businessmen in relation with the acquisition of diverse benefits in the transit of goods in the route towards Biscay and the Nervión estuary.

KEYWORDS: City; nobility; tax; market; Burgos; Velasco.

No cabe duda de que a finales de la Edad Media las ciudades supusieron un polo de atracción económica para la nobleza por lo que éstas suponían a nivel de inmersión en el mercado urbano, participación en la compraventa de productos y abastecimiento a la ciudad, control y gestión de instrumentos fiscales, adquisición de negocios, etcétera ${ }^{2}$. Dentro de esta perspectiva, Burgos no constituye ninguna excepción ${ }^{3}$. La Caput Castellae concentró a un número considerable de nobles que participaron en las distintas esferas del mercado burgalés.

2. Así, por ejemplo, lo expresaba $\mathrm{M}^{\mathrm{a}} \mathrm{C}$. Quintanilla Raso: "está suficientemente demostrado hasta qué punto los miembros de la cúspide nobiliaria sintieron la necesidad de asentarse en las más importantes ciudades castellano-leonesas, no sólo por razones políticas, sino para introducirse en los circuitos y presupuestos de la economía ciudadana, redes mercantiles, sector servicios, explotación de inmuebles, casas, tiendas, etcétera.”; Quintanilla Raso 1999, pp. 287-288. Recientemente incidía en esta cuestión Ignacio Álvarez Borge, en un trabajo en el que examinaba la proyección económica de la nobleza en las ciudades, incorporando referencias a propósito del interés de los nobles por participar en los mercados o en el sistema crediticio; Álvarez Borge 2016. Fundamentales para el estudio de la nobleza en Castilla resultan los trabajos de: Álvarez Borge 1996, 1997, 2001 y 2010; Beceiro Pita 1998; Beceiro Pita y Córdoba de la Llave 1990; Cabrera Muñoz 1977; Cabrera Sánchez 1998; Díaz de Durana 1998; Franco Silva 1997, 2006c; Gerbet 1989; Ladero Quesada 1998; Quintanilla Raso 1979, 1982, 1984, 1999, 2004 y 2006; Palencia Herrejón 1995; Suráez Fernández 2003; VV. AA 1999. Dentro del estudio de la relación de la nobleza con los marcos urbanos destacan entre otros: Álvarez Álvarez 1999; Asenjo González 2009 y 2013; Diago Hernando 1992, 2007, 2009 y 2014; Jara Fuente 1997, 2013 a y b y 2017; Millán da Costa y Jara Fuente 2016; Monsalvo Antón 2008 y 2013; Ortega Cervigón 2003 y 2011. Un estado de la cuestión al respecto puede consultarse en: Montero Málaga 2017c.

3. La ciudad de Burgos ha sido objeto de una profusa atención historiográfica, algunos de los trabajos fundamentales que abordan el estudio de este concejo son: Bonachía Hernando 1987 y 1988 ; Casado Alonso 1987; Guerrero Navarrete 1984; Guerrero Navarrete y Sánchez Benito 1990. Asimismo, es posible encontrar en los mismos referencias a la presencia de la nobleza en la ciudad: Bonachía Hernando 1988, p. 341-355, en donde el autor recoge en su estudio sobre el señorío colectivo ejercido por Burgos, los conflictos que la Caput Castellae habría mantenido con algunos linajes presentes en la comarca burgalesa como los Velasco, los Sarmiento o los Rojas; Casado Alonso 1987, pp. 442-150, en las que se recogen menciones a los Sarmiento, los Velasco, los Rojas, los Carrillo Muñoz, los Hurtado de Mendoza o los Manrique; Guerrero Navarrete 1984, pp. 146-154 para la nobleza local. 
Hasta 1476 la presencia y participación política de la alta y media nobleza en Burgos fue ocasional, fundamentalmente con motivo de su intervención en los asuntos de la alta política castellana: convocatoria de cortes, embajadas, defensa de la ciudad en el contexto de los enfrentamientos monarquía-nobleza durante los reinados de Juan II y Enrique IV, etcétera. A pesar de ello, no faltan ejemplos que remiten al interés de la nobleza por participar en la economía urbana, especialmente a través del abastecimiento a la ciudad desde sus villas señoriales, caso de las casas de Mendoza, Manrique o Acuña, entre otros, según tendremos ocasión de comprobar ${ }^{4}$.

Una salvedad la constituye el linaje de los Estúñiga, duques de Arévalo, condes de Plasencia y alcaides del castillo burgalés desde 1391, quienes disponían de una casa-palacio en Burgos, además de contar con una amplia red de acostados en la ciudad, si bien su relación con el concejo y vecinos burgaleses estuvo marcada por el conflicto ${ }^{5}$. También residieron de manera semipermanente en la ciudad los adelantados mayores, al ser Burgos la capital del adelantamiento de Castilla, caso de Gómez Manrique y de su esposa Sancha de Rojas, vecinos del barrio de San Esteban, y los mariscales Sancho de Estúñiga y García López de Ayala ${ }^{6}$. Aunque ninguno de estos notables ocupó ningún oficio regimental en la ciudad.

Por el contrario, el reinado de los Reyes Católicos supuso un periodo de afianzamiento de la presencia de la nobleza en la ciudad. El nombramiento de Sancho de Rojas, señor de Cavia y de Monzón como merino mayor de Burgos en 1477, junto con la concesión de una regiduría para su hijo Diego como compensación por la ayuda prestada a los monarcas en el conflicto sucesorio, representaba el acceso por primera vez de la nobleza al concejo. A partir de entonces, se documenta a la nobleza ocupando algunos oficios municipales durante este reinado, bien de manera directa o bien a través de sus criados y servidores. En paralelo, fueron varias las casas señoriales que establecieron su residencia permanente en la ciudad, como los Sarmiento, condes de Salinas, quienes mantuvieron diversos acuerdos con el concejo por la venta de sal desde su villa de Salinas de Añana ${ }^{7}$ También se incrementó la presencia en la ciudad de los Manrique, duques de Nájera, que no consiguieron avecindarse en la Caput Castellae, aunque sí lo hicieron sus parientes, los señores de Escamilla. Pero, sobre todo, destaca la acción en Burgos de los Velasco, condes de Haro (1430), condestables de Castilla (1473) y duques de Frías (1492), quienes gozaron de una notable influencia en la ciudad, y en particular en su estructura política, desde 1470, momento en el que decidieron establecer su residencia permanente en Burgos ${ }^{8}$. Centraremos nuestro estudio en este linaje, examinando su intervención en la economía y mercado urbano.

4. Una síntesis de la presencia de la nobleza en Burgos puede encontrarse en Montero Málaga 2017 b.

5. Montero Málaga 2012, pp. 72-89 y Guerrero Navarrete 2017.

6. Montero Málaga 2017b, p. 153-155.

7. Sebastián Moreno 2013.

8. Montero Málaga 2017a y Paulino Montero 2015. 
No obstante, la ausencia de fuentes hace de éste un tema especialmente complejo de analizar. Aunque para el caso castellano cada vez se dispone de mayor información acerca de las haciendas señoriales, los niveles de renta, la gestión de las mismas, los aspectos relativos a la planificación económica de los señoríos o incluso lo que éstas supusieron a nivel político y social, habiéndose superado viejos tópicos historiográficos en torno a la nobleza, como su "despreocupación económica" o "la falta de previsión del gasto señorial", , son muchas las lagunas que existen sobre las haciendas señoriales debido a la escasez de fuentes hacendísticas anteriores al siglo XVI ${ }^{10}$. En el caso de la casa de Velasco, si bien se ha conservado una información hacendística significativa ${ }^{11}$, que ha permitido reconstruir con cierto éxito la hacienda señorial (nivel de gastos e ingresos) así como los mecanismos de gestión de la misma ${ }^{12}$, es mucho lo que se desconoce debido a la ausencia de registros contables. Un ejemplo paradigmático lo constituye la renta de los diezmos de la mar, pues no es posible reconstruir de manera secuenciada desde 1469 la cuantía total que los titulares del linaje percibieron por esta renta ${ }^{13}$.

Si esto es así para las principales fuentes de ingresos de la hacienda señorial, tanto o más puede decirse en lo que respecta a la participación del linaje en la

9. Yun Casalilla 2002, pp. 11-13.

10. Al respecto de esta cuestión, con ánimo de no extender más el aparato crítico, remitimos al análisis que realiza al respecto Muñoz Gómez 2016, pp. 431-439. En el mismo, el citado autor incluye referencias a los registros contables que se han conservado para las casas señoriales, siendo escasos los anteriores a 1450-1480. Así, el autor menciona fuentes y trabajos de referencia, como los de Quintanilla Raso, los de Beceiro Pita para el condado de Benavente, los de Martínez Moro o Gerbet que incorporan datos sobre la hacienda de los Estúñiga, los de Ladero Quesada para los Guzmán, etcétera. Además, acertadamente, el autor relaciona la cuestión de la conservación documental con la sociogénesis de la aristocracia medieval.

11. Aunque hasta la segunda década del siglo XVI no se conservan cuentas detalladas de los gastos señoriales, es posible reconstruir esta información a través de las cartas de pago, cesiones de bienes, compraventas o incluso a partir de las mandas testamentarias conservadas en el fondo de los Duques de Frías. Asimismo, estos datos pueden complementarse con los fondos de la Escribanía Mayor de Rentas o de Contaduría de Mercedes del Archivo General de Simancas, muy útiles para conocer las sumas que percibían los miembros de la casa señorial de los privilegios regios o libranzas por sus cargos. Además, para el siglo XIV contamos con la información que proporciona el "Libro Becerro de las Behetrías" fundamental para el análisis de los tipos de ingresos fiscales procedentes de las 534 entidades de población sobre las que los Velasco poseían algún tipo de derecho en la merindad de Castilla Vieja, en donde eran titulares de 43 behetrías, 56 diviseros, 26 pueblos de solariego y poseían más de 38 heredades. Para esta última cuestión remitimos al trabajo de Esther González Crespo, que toma como base el Becerro para analizar el patrimonio señorial; González Crespo 1986.

12. Sirvan de ejemplos los trabajos elaborados al respecto para la casa de Velasco, sobre todo: Franco Silva 2006a. De interés para el conocimiento de los oficiales relacionados con la economía señorial (contadores, mayordomos, tesoreros...) Franco Silva 1996. En este último trabajo además se incluyen numerosos datos acerca de las haciendas de varios nobles castellanos del siglo XV. Resultan particularmente reseñables en lo que se refiere a las fuentes de ingresos de las casas señoriales y a la transmisión del patrimonio; Moreno Ollero 2014, pp. 328-330 y Pereyra Alza 2014, pp. 249-274. Este último también para el estudio de los oficiales encargados de la administración y gestión hacendística.

13. Y mucho menos contamos con una amplitud de datos acerca de la recaudación de los mismos o de su arrendamiento. Así lo señalaba Alfonso Franco Silva: "Por desgracia carecemos de información sobre los beneficios que los diezmos de la mar aportaron a las arcas del primer Condestable y a las de sus sucesores. Ningún documento hace referencia a este interesante aspecto de la fiscalidad señorial. El Archivo Ducal de Frías resulta a este respecto particularmente silencioso", Franco Silva 1996, p. 261. 
economía burgalesa, a pesar del peso que adquiere la presencia de esta casa señorial en la urbe desde las últimas décadas del siglo XV. En este sentido, apenas se conservan noticias que permitan examinar las relaciones económicas sostenidas con el concejo burgalés en los fondos documentales conservados para esta casa. Tampoco en los libros de actas municipales. En aquellos casos en los que contamos con documentación referente a la participación de los miembros del linaje en algún ámbito de la economía urbana, la información apenas supera las dos líneas y se presenta descontextualizada, lo que nos impide profundizar en el análisis de la misma. Así ocurre, por ejemplo, con una entrada del año 1452 en la que se menciona cómo el I conde de Haro, Pedro (II) Fernández de Velasco, habría impuesto un estanco sobre la renta urbana de la barra ${ }^{14}$. No obstante, al margen de este dato, no podemos adentrarnos más en el examen de este asunto ${ }^{15}$.

Con todo, disponemos de algunas noticias que permiten examinar la participación de la casa señorial en la economía urbana en torno a dos cuestiones. En primer lugar, en relación con la fiscalidad regia. En concreto, con la percepción de los privilegios que los titulares del linaje tenían situados en las alcabalas de Burgos, así como con el arrendamiento de estas rentas por parte de Pedro de Velasco $(†$ 1518), hijo bastardo de Bernardino Fernández de Velasco († 1512), I duque de Frías y III conde de Haro.

Por otro, los titulares del linaje habrían participado en el mercado burgalés desde distintas áreas. En primer lugar, a través del abastecimiento de productos a la ciudad, en particular de cereal y vino. En segundo lugar, negociando con la ciudad y con la corona exenciones fiscales para la compraventa de productos en la ciudad. Y, finalmente, cooperando con los mercaderes y hombres de negocios burgaleses en el territorio vizcaíno para el aprovechamiento conjunto de los flujos comerciales de la Ría del Nervión.

\section{LOS VELASCO Y LA FISCALIDAD REGIA: PERCEPCIÓN Y ARRIENDO DE LAS RENTAS REALES DE BURGOS}

Probablemente, uno de los ámbitos al que se alude con mayor frecuencia cuando se analiza en el caso castellano la relación económica de la nobleza con las ciudades es el que vincula a los nobles con las rentas reales de un determinado municipio. Es de sobra conocido cómo alcabalas, tercias, pedidos o monedas sirvieron para satisfacer los pagos de juros, raciones o sueldos debidos por la mo-

14. La barra agrupaba varias rentas, fundamentalmente gravámenes sobre el tráfico de mercancías o la compraventa de productos.

15. Concretamente la noticia hace referencia a cómo el arrendador Juan García de Padrastro solicitaba al regimiento que le descontasen el porcentaje que debía del arrendamiento de la renta de la barra, puesto que había perdido dinero por el estanco que les había impuesto el conde de Haro. Además, el arrendador argumentaba cómo habría tenido graves pérdidas a causa de la estancia del rey en la ciudad, por no haber podido pesar en cuaresma y por la falta de carne que había padecido Burgos. AMB, LLAA, 1453, ff. 30v, 31r, 45v, 46r y 49r. 
narquía a las distintas instituciones o particulares. Para la nobleza, el pago de estas cuantías venía a suponer una importante fuente de ingresos dentro de sus haciendas señoriales ${ }^{16}$. En las ciudades, generalmente fue la alcabala la renta que sirvió para situar el pago de estas cantidades que la corona tenía que abonar a los distintos nobles usualmente por tres motivos principales. Por un lado, como resultado de la concesión de una merced en compensación por un servicio prestado, lo cual normalmente se traducía en la concesión de un privilegio o juro en el que se estipulaba la cuantía a deber, el tiempo por el que se iba a percibir y el lugar donde se iba a cobrar. Por otro, a cuenta de las libranzas de los pagos de acostamientos o de salarios percibidos por el oficio que un determinado noble ocupaba dentro de la casa real. Finalmente, por la compra del noble de un título de deuda sobre esas rentas, caso de los juros al quitar.

Este fenómeno, que se conoce bien para muchas ciudades del realengo castellano, no fue ajeno a Burgos ${ }^{17}$. Baste como ejemplo los 25.000 maravedíes que los Velasco tenían situados en las rentas reales de Burgos del total de los 67.000 de salario que recibían por la condestablía. En concreto, estos 25.000 maravedíes se encontraban situados sobre las rentas de las alcabalas del vino, joyas y pellejería, segunda venta del haber de peso, sebos y zumaques, la madera, las heredades y la alcabala de las carnicerías con la carne viva ${ }^{18}$. Además de las cantidades que a los miembros del linaje les fueron libradas como salarios en la ciudad de Burgos y su partido, los Velasco obtuvieron también como compensación por el servicio que prestaron a la monarquía en los siglos XIV y XV toda una serie de juros (anuales o de heredad) asentados en estas alcabalas sobre los que podían disponer libremente, teniendo incluso capacidad para cambiarlos, traspasarlos o venderlos ${ }^{19}$. Sirva de

16. Acerca de esta cuestión, su importancia dentro de las haciendas señoriales o el procedimiento de cobro de estas cantidades en relación con la tasa de señorío a partir de 1454, sirvan los trabajos: Ladero Quesada 1972, pp. 75-84; 1982, pp. 68-74; Quintanilla Raso 1982, pp. 767-798 y Yun Casalilla 1991, pp. 73-105. Para una hacienda señorial concreta, resulta interesante el trabajo de Víctor Muñoz sobre la casa de Fernando de Antequera y Leonor de Alburquerque, en donde se observa cómo el mayor aporte de ingresos procede de las cuantías detraídas a la hacienda real; Muñoz Gómez 2016, pp. 441-448. En el caso de los Velasco, Antonio Moreno también recoge la importancia de estos ingresos dentro de la hacienda señorial en tiempos del I conde de Haro. Si bien en este último caso se trata de un análisis muy somero; Moreno Ollero 2014, pp. 328-330.

17. Valga de ejemplo el artículo de Juan Manuel Bello sobre Sevilla: Bello León 2014, pp. 211-239. De igual manera, algunos datos acerca los maravedíes que percibían varios miembros de la nobleza castellana sobre las rentas regias en la ciudad de Valladolid pueden consultarse en: Ruquoi 1982, pp. 799-822. También Margarita Cabrera incluía en su análisis sobre Córdoba información sobre los juros que poseía la nobleza en la ciudad, sobre todo los Fernández de Córdoba: Sánchez Cabrera 1998, pp. 255-281. Un último ejemplo que podría ser citado es el caso de Cuenca: Ortega Cervigón 2006, pp. 288-290. En el caso de la ciudad de Burgos puede citarse aquí el trabajo de Carlos Álvarez, pues incorpora algún dato sobre el periodo anterior, aunque principalmente la cronología en la que se centra este trabajo es posterior a nuestro artículo. En concreto, las páginas pp. 142-163 contienen un listado de los juros al quitar situados en las alcabalas de Burgos; Álvarez Nogal 2009, pp. 142-163. Finalmente, un ejemplo del interés de los Velasco en otras villas del realengo puede encontrarse en San Vicente de la Barquera y la alcabala del pescado; Añíbarro Rodríguez 2013, pp. 110-111.

18. Así aparece en un privilegio conservado de 1495; AHNOB, FRÍAS, caja 386, documentos 12-24. Además, un traslado de 1570, AHNOB, FRÍAS, c. 599, d. 22, f. 80rv.

19. AHNOB, FRÍAS, c. 597, d. 24. 
testimonio el albalá otorgado en junio de 1437 por Juan II a Pedro (II) Fernández de Velasco $(† 1470)$, I conde de Haro, por el que le facultaba para traspasar, trocar o cambiar 600 maravedíes que tenía situados en las rentas de la ciudad de Burgos. Aunque se trata de un ejemplo menor, nos permite documentar una tendencia que afectó a otros capítulos de renta más importantes, como se recoge en el testamento del I conde de Haro. En este documento se menciona cómo Pedro (II) Fernández de Velasco habría recibido de Juan II un privilegio de 25.300 maravedíes de juro de heredad en las alcabalas de la ciudad, que el I conde de Haro en 1447 había decidido traspasar al monasterio de Santa Clara de Medina de Pomar para el arreglo del tejado ${ }^{20}$. Del mismo modo, tenemos constancia de que en 1461 el I conde de Haro transfería 20.000 maravedíes que tenía por merced anual de juro de heredad en las alcabalas de Burgos al monasterio de San Bernardino de la villa de Cuenca de Campos, 15.000 en la alcabala del vino y 5.000 en la del pan ${ }^{21}$.

Sin embargo, más allá de las cuantías que acabaron situadas en las rentas de Burgos a tenor de los distintos juros que los sucesivos monarcas fueron concediendo a los miembros de la casa señorial, nos interesa referirnos aquí a esta cuestión atendiendo a cómo el interés por la percepción de estas cantidades obligó a los Velasco a acudir al concejo burgalés para que esta institución arbitrase justicia y les ayudase así a hacer efectivos sus privilegios sobre dichas rentas. De esta manera, a lo largo de nuestro período de estudio se documenta a los titulares del linaje, bien directamente o bien a través de sus intermediarios, normalmente de sus contadores, mayordomos o tesoreros mayores, reclamando ayuda para cobrar los maravedíes correspondientes a los juros, raciones o quitaciones que tenían situados en las rentas reales de la ciudad. Se trata del escalón más bajo en la cooperación entre ambas agencias, en el que, sin existir una dinámica de trabajo común destinada al alcance de un beneficio conjunto, la ciudad favorecería a los condestables al facilitar la recaudación de estos privilegios. Contamos con dos ocasiones en las que ha quedado constancia de esta cuestión.

En noviembre de 1441, Pedro Sánchez de Briviesca, contador señorial, solicitaba al concejo en nombre de Pedro (II) Fernández de Velasco que le diesen favor e ayuda e su mandamiento para que el conde pudiese cobrar los maravedíes que tenía situados en la renta del vino y del pan. Esta solicitud se realizaba después de que el arrendador mayor, Fernando Gutiérrez de Jerez, hubiese incumplido el pago de tales maravedíes ${ }^{22}$. Esto habría provocado que Pedro (II) Fernández de Velasco, como compensación por la pérdida de estos ingresos, ordenase el embargo de mercancías a los mercaderes que pasaban por sus tierras ${ }^{23}$. Por su parte, el concejo, a

20. AHNOB, FRÍAS, c. 598 , d. 13, f. 15 rv.

21. AGS, Mercedes y Privilegios, leg. 3, f. 78. Reg. Ladero Quesada, Olivera Serrano 2016, pp. 561-562.

22. "En este ayuntamiento se leyó una carta de Pedro Lopes de Sacta Maria sobre rasón de las prendas que se fasen en Beruiesca por los dineros que deue Ferrand Gutierres de Xeres, arrendador". AMB, LLAA, 1441, f. 26r.

23. "En este ayuntamiento Françisco Martines de Lerma dixo quel conde de Haro tenya embargados en su tierra panos de mercaderos desta çibdad, por ende que les desia que proueyesen en ello. Pedro Sanches de Frias dixo e requerió a los dichos alcaldes que proueyesen sobre la dicha rasón [...] 
fin de evitar estas represalias, exigía al merino la detención del arrendador hasta que el conde recibiese la cuantía debida. Sin embargo, en el mes de noviembre aún no se había procedido al pago de la misma, por lo que el conde de Haro enviaba a su contador a Burgos con el objetivo de demandar al concejo una solución. En esta ocasión, el concejo, haciendo uso de la jurisdicción de la que disponía para intervenir en materia de rentas reales, decretaba el embargo de dichas rentas para garantizar así al conde de Haro el cobro de sus maravedíes ${ }^{24}$.

Este ejemplo nos permite destacar dos ideas que por el momento nos limitamos a enunciar: por un lado, la preocupación de los condestables por cobrar sus cuantías y el recurso al concejo para tal fin, y, por el otro, la capacidad de actuación del concejo, que habría intervenido en el conflicto existente por la gestión de las alcabalas regias en favor de los condes de Haro, embargando las rentas del pan y del vino.

Una situación similar a la que acabamos de comentar se repetía en 1478, cuando Pedro de la Torre, maestresala de Pedro (III) Fernández de Velasco († 1492), II conde de Haro, requería al concejo burgalés mediante una carta de creencia que impartiese justicia ante las encubiertas y fraudes que se encontraba realizando el recaudador mayor de las alcabalas y tercias de Burgos, Juan de Figueroa, vecino de Toledo ${ }^{25}$. En concreto, en el proceso de licitación de la renta del vino.

Según lo expuesto por Pedro de la Torre, quien aseguraba haber estado presente en el momento de la puja, el recaudador mayor habría consentido que la cantidad alcanzada en el remate del arrendamiento por menudo de la renta del vino fuese menor a la necesaria para que le pudiesen ser abonados los maravedíes correspondientes ese año a los condes de Haro por los juros que tenían situados en

mandauan dar madamiento para que el merino prendiese al recabdador e lo pusyese en la torre de Sant Gil e que non lo de suelto nin fiado fasta que aya pagado al conde de Haro lo que paresçiere que le es deuido". AMB, LLAA, 1441, f. 72r.

24. "En este ayuntamiento veno Pedro Sanches de Briviesca en nombre del conde de Haro e dixo que los pidia que le diesen fauor e ayuda e su mandamiento para que el conde pudiese cobrar los maravedíes que el tiene en la renta del vyno lo qual dixo que daría mas largo por escripto. Mandaron dar su mandamiento para el merino e en tanto que esté embargada la dicha renta". AMB, LLAA, 1441, f. 91 r.

25. El 31 de diciembre de 1477, Lope González del Castillo, vecino de Burgos y arrendador de las alcabalas y tercias de Burgos del año de 1476, presentaba ante el concejo burgalés una carta de los Reyes Católicos, dada en Sevilla a 15 de diciembre, por la que se otorgaba a Juan de Figueroa, vecino de Toledo, poder para recaudar en fieldad las rentas reales de Burgos y de su merindad hasta que éstas fueran definitivamente rematadas. Como testigos comparecían Pedro González el Rico, Alonso del Castillo, hijo de Lope González de Castillo, y Fernando de Castro, hijo de Antón García. AMB, LLAA, 1478, ff. 2v-4r. El 6 de enero de 1478 los reyes autorizaban a Juan de Figueroa para arrendar y rematar las rentas reales de Burgos, su merindad y arcedianazgo sin la merindad de Rio Ubierna. Ese mismo día los monarcas otorgaban a Juan de Figueroa una carta real de recudimiento de las alcabalas y tercias del año de 1478. Ambas misivas eran presentadas por Juan de Figueroa el 27 de enero ante el concejo burgalés, que mostraba su disconformidad ante la aceptación de la carta de receptoría de las rentas reales, debido a los problemas que los años anteriores habían suscitado la aprobación de estas misivas. AMB, LLAA, 1478, ff. 8r-12r. Finalmente, el 5 de febrero el concejo permitía a Juan de Figueroa recaudar las rentas en fieldad y le autorizaba a arrendarlas con posterioridad en subasta pública sin fraude y con los prometidos legales. AMB, LLAA, 1478, ff. 13v-14v. Algunos datos más sobre las actividades arrendaticias de este vecino de Toledo pueden encontrarse en: Ortego Rico 2015b, pp. 251-253. 
las alcabalas de la ciudad. La renta habría recaído en el merino Alonso del Castillo, a pesar de que había habido postores que deseaban aumentar el precio de la puja y de que los condestables habían solicitado que, en consecuencia, se ampliase el plazo de licitación. No obstante, esta demanda no fue atendida, por lo que los juros de los condes habrían quedado invalidados ${ }^{26}$.

Además, la renta del vino no era la única afectada por esta situación. Las actas municipales registran protestas en torno al arrendamiento por menudo de la renta de la alcabala del pan, que se habría rematado en Pedro de Castro, con Pedro Rodríguez de Palencia como fiador, por 75.000 maravedíes, concediéndosele carta de recudimiento a pesar de que otros postores habían declarado su intención de pujar más alto por la misma. Llama la atención que entre los testigos presentes en el momento de presentar estas demandas por el remate de la renta del pan se encontrase el tesorero del condestable, García Rodríguez de Santa $\mathrm{Cruz}^{27}$. La presencia de este oficial indica el interés que los condestables tenían también en esta última renta y en el cobro de las cantidades situadas en la misma.

26. "Vino ende el maestresala del condestable con una carta de creençia del dicho señor condestable presente Pedro de la Torre la qual carta se dereia a Garci Rodríguez de Santa Crus su thesorero e non estando en la çibdad en por el dicho maestresala mostro una carta del dicho señor en la qual largamente se relataba el escreto de la creençia que era, que su señoría a sabido como en el faser de la renta Iohan de Figueroa recabdador mayor fase algunas encubiertas e fraudes e engaños de forma que sy aquello pasase él e la señora condesa perderían su juro. Que pide a la çibdad e a los señores alcaldes e regidores della que lo quieran remediar por que el non tenga rason descontar a la çibdad e cobrar lo suyo asy de los años pasados como deste e sobre lo qual, los dichos señores fablaron asas largamente con el deseo que tiene de seruir a sus altesas". A continuación, se debate en el regimiento sobre esta cuestión, piden a Pedro de la Torre, por guardar el servicio del rey, que relate los fraudes que se estaban cometiendo para poder remediarlos. "E luego el dicho Pedro de la Torre dixo que el luego de esto que la renta del vino estando el presente la querían rematar e que pidió e requirió que la dexasen abierta en el día fasta medianoche e que nunca lo quisieron faser e la remataron non embargante al dicho su requerimiento por donde el dicho situado del dicho señor condestable e de la dicha señora condesa non cabia en la dicha renta e que las otras cosas que el sabia tocantes a otros fraudes e engaños [...] E luego el merino Alonso del Castillo dixo que porque su situado que el tyene cupiese el fiso pujar la renta del dicho bino e al que la puso en su nombre gela auian arrendado de todo remate, pero por acatamiento de la çibdad e por servicio del dicho condestable como quier que se le fase preuisio e agrauyo que el consiente que la dicha renta se abra e este abierta por toda esta semana complida que agora estamos por que la puje quien quisiere". AMB, LLAA, 1478, f. 19rv.

27. "Por cuanto la çibdad se quexó del arrendamiento de la renta del pan de los dos años con las salidas desta çibdad que el dicho Fernando de Cuebas Ruvias arrendó al dicho Pedro de Castro segund que pasó por ante mí el dicho escribano especialmente porque es en preuisio e daño de la çibdad arrendar por dos años la dicha renta e porque se fallaba quien más diese por la dicha renta este año con la dichas salidas [...] El dicho Fernando de Cuebas Ruvias en nombre de la dicha çibdad e por el poder que tiene de la dicha çibdad tornó a arrendar la dicha renta en el dicho Pedro de Castro con las salidas del pan deste año en setenta e cinco mil maravedíes e dando fianças llanas e abonadas mandóle dar recudimiento. Luego el dicho Pedro de Castro como prinçipal e arrendador e debdor e Pedro Rodriguez de Palençia como su fiador otorgan e conosçen que toman a renta de la dicha çibdad las dichas rentas de alcabala del pan e las salidas de la llana por preçio e quantya de setenta e cinco mil maravedíes e se obligaron de los dar e pagar por los tercios del año a saber a los dueños de los privileios lo que esta saluado en la alcabala del pan e la demasya del dicho salvado de lo dar asimismo al dicho mayordomo desta çibdad que es Alonso de Porres por los dichos tercios del año [...] Testigos: el tesorero Garci Rodríguez de Santa Cruz, e Sancho de Santa María, e Pedro García de Media, escribano vesino de Burgos". AMB, LLAA, 1478, f. 13rv. 
En cualquier caso, se desprende del testimonio del maestresala cómo estos remates se habrían producido con el consentimiento de Juan de Figueroa, o al menos sin que él hubiese intervenido para evitarlos, tal y como le obligaba su cargo de recaudador mayor, ya que en esta figura recaía la capacidad de otorgar las cartas de recudimiento que terminaban facultando a estos arrendadores para su tarea. Así, la labor del recaudador mayor exigía un control sobre estos arrendamientos por menudo, a fin de garantizar que recayesen en el mejor arrendador y que no se cometiesen irregularidade ${ }^{28}$. En consecuencia, ante la falta de control y supuesto consentimiento de Juan de Figueroa que habría consentido acortar el tiempo estipulado para el remate de las rentas, estos acontecimientos terminaron motivando la demanda interpuesta por los condes de Haro a través de Pedro de la Torre, que solicitaba el concurso del concejo para la resolución de esta situación irregular.

Por tanto, el concejo se veía obligado a intervenir en el asunto, optando, junto con el merino de la ciudad y por servir al rey y al condestable, por permitir que la licitación por la renta del vino se abriese de nuevo durante toda una semana. Además, se establecía una comisión que debía investigar los posibles fraudes realizados por Juan de Figueroa en el remate de las rentas y en sus prometidos ${ }^{29}$. En síntesis, este segundo ejemplo nos permite comprobar una vez más cómo el concejo habría favorecido a los condestables, facilitándoles el disfrute de sus privilegios.

De entrada, es evidente que ambos ejemplos nos permiten conocer de manera detallada cómo se producía el arrendamiento por menudo de estas rentas y quiénes fueron los agentes implicados en ellas, desde el recaudador mayor hasta el arrendador o fiador de la renta en la ciudad. Pero, sobre todo, manifiestan la capacidad de intervención concejil en materia de rentas reales, especialmente en el caso de la existencia de problemas en torno a la gestión de las mismas. El concejo participaba tanto en los aspectos ejecutivos del cobro de las rentas como en materia judicial. De este modo, no sólo tenía capacidad para ordenar la reapertura de una licitación, tal y como hizo en 1478, sino que se encontraba facultado para dirimir los posibles problemas de abusos o fraudes cometidos por los agentes fiscales. Incluso, el concejo tuvo capacidad para apresar o suspender a estos oficiales en su cargo, como se ha observado para el caso de Fernando Gutiérrez de Jerez en $1441^{30}$.

Por tanto, el concejo no sólo se encontraba fiscalizando la labor de los agentes que participaban en la recaudación y arriendo de estas rentas interviniendo judicialmente ante estos fraudes, sino que mediante estas acciones velaba por los intereses de los receptores finales de las cuantías, en este caso los condes de Haro, que accedían al cobro de las mismas gracias a sus privilegios. Además, el concejo respaldaba sus actuaciones bajo la noción del "servicio" que la ciudad prestaba, no

28. Acerca de este proceso en la ciudad véase: Guerrero Navarrete 1986b, pp. 491-492; 1986a, pp. 218-227.

29. AMB, LLAA, 1478, f. 19v. Ya en febrero el concejo encargaba al alcalde Alonso Díaz de Cuevas investigar los rumores existentes sobre los fraudes cometidos en el remate de las rentas, que habrían sido acortados, y en sus prometidos. AMB, LLAA, 1478, f. 15. Sobre los fraudes acontecidos en los procesos de licitación de las rentas regias consúltese: Ortega Cera 2010; Ortego Rico 2012 y 2015a, pp. $188-189$ y 360-370.

30. Guerrero Navarrete 1986b, pp. 488-490. 
sólo a los condestables, sino fundamentalmente al monarca y la hacienda real, que en caso contrario no percibiría las cuantías derivadas de estos impuestos.

Asimismo, los dos ejemplos extraídos demuestran de manera clara cómo los Velasco conocían con precisión tanto su patrimonio como las fuentes de ingresos de su hacienda señorial, sobre las que mantenían una estrecha vigilancia ${ }^{31}$. Más allá de la lectura que estos documentos nos permiten realizar sobre el conocimiento que los cabezas del linaje, mayordomos, tesoreros o contadores señoriales podían tener sobre las cantidades que debían percibir de unos u otros territorios ${ }^{32}$, ambos ejemplos nos acercan al estudio de la hacienda señorial y su gestión. A través de los mismos es posible intuir el sistema de vigilancia que los Velasco desplegaron sobre estas rentas, con el objetivo de garantizar la total percepción de los privilegios que tenían situados en esas alcabalas. Sin duda, esta situación requería de una cierta planificación, así como de la disposición de agentes destinados para tal fin, o en su defecto, de una amplia red de informantes que les permitiese conocer el estado de la licitación de las rentas reales y la cantidad en la que finalmente se habían rematado.

En lo que toca a los documentos expuestos, especialmente para 1478, nos decantamos por la primera opción, ya que el propio Pedro de la Torre afirmaba haber estado presente en el momento del remate de la renta del vino, y así es posible documentarlo, al menos la tarde del día en que esa renta fue rematada ${ }^{33}$. De igual manera, el maestresala del condestable aparece registrado en esos documentos como vecino de la ciudad, lo que implica que probablemente debía residir en Burgos, si no de manera permanente al menos durante algunos períodos. También durante esas fechas se menciona al tesorero mayor del II conde de Haro, García Rodríguez de Santa Cruz, como testigo de las demandas presentadas por el remate de la renta del pan en Pedro de Castro ${ }^{34}$.

Por otra parte, en relación con estos oficiales señoriales, es necesario señalar cómo ambos comparten apellidos con dos familias burgalesas judeoconversas, de la Torre y Santa Cruz, vinculadas a la actividad mercantil y financiera. En lo que respecta a los de la Torre, emparentados familiarmente con otro linaje de la élite burgalesa, el de los Castro $^{35}$, es posible documentarlos formando parte del regimiento del Arlanzón desde 1471, con Fernando de la Torre como regidor ${ }^{36}$. Este

31. Tema que ya ha demostrado Cristina Jular para finales del siglo XIV a través del análisis de la donación realizada por María Sarmiento, esposa de Pedro (I) Fernández de Velasco, al mayordomo don Haly. Un testimonio en el que, como bien ha analizado la autora, se comprueba cómo los miembros del linaje no sólo poseían un conocimiento detallado sobre los territorios que integraban su patrimonio, sino también sobre la forma en que éstos se encontraban administrados; Jular Pérez-Alfaro 2013, p. 70.

32. Así se observa, por ejemplo, en los testamentos familiares, en los que sin ir más lejos suelen aparecer detalladas estas cuantías entre los bienes a heredar o las mandas testamentarias. Baste como muestra el testamento del I conde de Haro, por el que Pedro (II) Fernández de Velasco daba instrucciones a su oficial de los libros, Juan Fernández de Melgar, para que dispusiera sobre diversos juros situados en las alcabalas de distintos territorios. Porres Fernández 2009, pp. 91-95.

33. AMB, LLAA, 1478, f. 2r.

34. AMB, LLAA, 1478, f. 13rv.

35. Carvajal de la Vega 2011, pp. 91-92.

36. Guerrero Navarrete 1986a, p. 177. 
último fue sucedido en el cargo por su hermano el doctor Juan de la Torre, mercader que en la década de 1490 operó en Bretaña e Inglaterra ${ }^{37}$. También perteneció a esta familia Pedro de la Torre, regidor entre 1514 y 1555, quien formó compañía comercial con los burgaleses Alonso de Astudillo y Lope Pérez de Maluenda ${ }^{38}$. Si nos referimos a los Santa Cruz, podría decirse que se trató de una familia menor de mercaderes burgaleses, destacando dentro de la misma la figura de Álvaro Rodríguez, quien fue hijo de García Rodríguez, tesorero del condestable ${ }^{39}$.

Hasta finales del siglo XV la presencia de vecinos de la ciudad del Arlanzón entre los oficiales de la casa de Velasco fue escasa. En su testamento, otorgado en 1418, Juan Fernández de Velasco había dispuesto que el cargo de recaudador recayese siempre en los vasallos del señorío y vecinos del lugar que éstos iban a administrar, condición que mantuvo su hijo el I conde de Haro a la hora de elegir nuevos oficiales, así como miembros de la hueste señorial ${ }^{40}$. Por el contrario, en tiempos del II conde de Haro, si bien muchos de los oficiales procedían de las villas del señorío, es posible comprobar entre los mismos a naturales de la ciudad de Burgos $^{41}$, caso de Pedro de la Torre y García Rodríguez de Santa Cruz. Además, es posible documentar a otro "de la Torre", vecino de Burgos, en el circulo del condestable, Álvaro de la Torre, mencionado como "fasedor" de Pedro (III) Fernández de Velasco en varios documentos ${ }^{42}$. En su elección, es posible que los condestables considerasen la mayor facilidad que estos oficiales, por residir en Burgos, podrían tener a la hora de vigilar el proceso de recaudación de estas rentas y si se iban a garantizar los pagos de las cuantías que los condestables tenían situados en las mismas. En cualquier caso, la designación de estos dos oficiales se inscribe dentro de un proyecto más amplio de "recentralización administrativa" que el II conde de Haro y su esposa habrían diseñado en torno a la Caput Castellae, al convertirla

37. Caunedo del Potro 1981, pp. 174-175.

38. Carvajal de la Vega 2013, p. 268. También menciona la existencia de esta compañía el profesor Hilario Casado en: Casado Alonso 2011, p. 28. Además, es posible encontrar otras referencias a los miembros de estos dos linajes en los diversos trabajos que ambos autores han dedicado al estudio del comercio castellano. De igual modo, conviene señalar al linaje "de la Torre", documentado en Toledo, cuyos miembros se dedicaron fundamentalmente a las actividades financieras. Ortego Rico 2015a, pp. 574-576.

39. Caunedo del Potro 1981, pp. 122-130 y 225-226. De manera semejante a lo anotado para los "la Torre", se documenta la existencia del linaje Santa Cruz en Aranda de Duero. En concreto, es obligatorio mencionar al arrendador judeoconverso, Pedro de Santa Cruz, arrendador en 1484-85 de la merindad de Santo Domingo de Silos, además de formar compañía en 1512 para arrendar por cuatro años el almojarifazgo de Sevilla. Diago Hernando 1991, pp. 73-78. Asimismo, es posible encontrar información acerca del mismo en: Alonso García 2006, pp. 117-138.

40. Franco Silva 2006a, p. 138; Moreno Ollero 2014, pp. 291-292; Pereyra Alza 2014, p. 251. Además, la disposición consignada en el testamento de Juan Fernández de Velasco puede consultarse en AHNOB, FRÍAS, c. 596, d. 12, ff. 13v-14r.

41. Montero Málaga 2017a, p. 353-355.

42. De esta manera aparece registrado en las actas municipales de 1480, a causa de los problemas que este oficial señorial estaba causando a la villa de Mazuela, dependiente jurisdiccionalmente del concejo del Arlanzón; AMB, LLAA, 1480, f. 9v. En 1503, un Álvaro de la Torre aparece como criado del condestable en un pleito relativo a unas tierras de Bernardino Fernández de Velasco; AGS, CCA, Personas, leg. 7-1, f. 377. Cuatro años después es posible documentarlo presentando unas cláusulas relativas al testamento del II conde de Haro; AHNOB, FRÍAS, c. 495, d.2. 
a partir de la década de los setenta del siglo XV en el centro simbólico, político y administrativo del señorío. A través fundamentalmente de la erección del palacio del Cordón, que fijaría su residencia permanente en la urbe, y la elección de un nuevo complejo funerario en la capilla de la Purificación de la Catedral ${ }^{43}$.

Finalmente, en lo que respecta a la participación de los Velasco en el arrendamiento de rentas reales, apenas se conserva información sobre esta cuestión, salvo los datos registrados para Pedro de Velasco, hijo bastardo del I duque de Frías Bernardino Fernández de Velasco. Nos interesa incorporar aquí estas noticias, puesto que Pedro de Velasco habría arrendado aquellas rentas en las que los Velasco tenían privilegios situados, lo que podría haber beneficiado de algún modo a la hacienda señorial. Sin embargo, en este caso no se observa ningún intento de cooperación entre la ciudad y miembros de la casa señorial, aunque Pedro de Velasco pudo participar en estos procesos gracias a las conexiones que mantendría con la élite burgalesa, de la que también formaba parte al ser nieto del regidor Pedro Orense.

Entre finales de la década 1480 y primeros años del siglo XVI, Pedro de Velasco pujó y arrendó por menudo algunas de las rentas en las que los Velasco tenían situados maravedíes, como la del vino o las joyas. Así se observa para los años de 1488 y 1489, en los que arrendó la renta de las joyas y peletería ${ }^{44}$. También en 1496 arrendaba la alcabala de la peletería junto con la de las viñas ${ }^{45}$. Igualmente, en 1497 recaía en Pedro de Velasco la renta de las joyas y peletería y la de los paños, sobre la que mantuvo un pleito por el impago de las alcabalas con los mercaderes y vecinos de Toledo, Juan y Bartolomé Sánchez de San Pedro ${ }^{46}$. En 1500, él y su hijo se encontraban involucrados en un litigio sostenido con los arrendadores y recaudadores de las alcabalas y tercias de Burgos del trienio de 1501 a 1503, Francisco de Villena, Alonso Ramírez y Luis Núñez Coronel por la puja de la renta de las alcabalas de las joyas ${ }^{47}$. Un año después, Pedro de Velasco debió de arrendar la renta del haber de peso con Andrés de Diago, dejando incumplidos los pagos, tal y como registra una noticia de 1509 por la que se señala cómo debían a la ciudad unos 53.000 maravedíes por la renta de dicho año de $1501^{48}$.

43. Acerca de la "recentralización simbólica" véase: Paulino Montero 2015, pp. 124; 279 y 433. Para la cuestión administrativa: Montero Málaga 2017a, pp. 500-538.

44. ARChVa, Ejecutorias, c. 112, exp. 18.

45. AMB, LLAA, 1496, f. 36r.

46. AGS, RGS, leg., diciembre de 1499, f. 128.

47. AGS, RGS, leg., octubre de 1500, f. 255. Ya en 1490 Luis Núñez Coronel se habría encargado de la recaudación del partido de Burgos, tal y como recoge Ortego Rico en el artículo que dedica a este financiero judeoconverso. Ortego Rico 2018. Además, véase: Ortego Rico 2015a.

48. "Estando los dichos señores en su ayuntamiento paresçió presente Francisco Blazquez juez de cuentas por la reyna nuestra señora e dixo que él por virtud del poder que de su alteza tiene bió un contrato e obligación por el qual paresçia que los bienes de Pedro de Belasco e Andres de Diago estaban obligados de mancomún e cada uno para el todo por obligaçión fecha ante Diego de Valladolid lugarteniente de escribano de rentas por quantia de çinquenta e tres mil maravedíes de resto de la dicha obligaçión que estaban obligados a la dicha çibdad de la renta del aver peso del año de mil e quinentos e uno". AMB, LLAA, 1509, ff. 92v y 93r. También proporciona información acerca de este asunto una carta de la reina Juana I conservada en la sección de Pueblos de la Cámara de Castilla del Archivo 


\section{La casa de Velasco y el mercado de Burgos}

A finales de la Edad Media es posible documentar la participación de los miembros de la casa señorial en dos ámbitos que afectan al mercado burgalés, los cuales se examinan a continuación. Por un lado, la participación de los Velasco en el abastecimiento urbano, cuestión que con frecuencia terminó derivando en pleitos sostenidos entre los condestables y el concejo urbano tanto por las condiciones impuestas para la venta de las mercancías procedentes de los territorios del señorío en la ciudad como por el incumplimiento de los términos acordados por el abastecimiento de un determinado producto por una u otra parte. Por otro lado, a través de la cooperación sostenida entre los titulares del linaje y los hombres de negocios burgaleses en el tránsito de mercancías en la ruta hacia Bilbao y el Cantábrico.

\subsection{La participación en el abastecimiento urbano ${ }^{49}$}

Entre finales del siglo XV y principios del XVI es posible comprobar cómo fueron varias las villas nobiliarias que abastecieron a la ciudad desde sus señoríos como Roa, Aranda, Becerril, Haro, Palenzuela o Dueñas, centros de desarrollo de la producción vitícola ${ }^{50}$.

Así, en 1453 y 1462 Ruiz Díaz de Mendoza y su esposa tramitaron la compra de vino desde su villa de Castrojeriz ${ }^{51}$; en 1461, 1492, 1497 y 1499 era el conde de Buendía, Pedro de Acuña, el que demandaba al concejo burgalés que comprase vino de Dueñas ${ }^{52}$; en 1463 la solicitud la realizaba el conde de Castro para la venta de vino de Gumiel ${ }^{53}$; mientras que en 1486 lo hacía el duque de Nájera para Amus$\mathrm{co}^{54}$. Además de vino, los nobles negociaron el abastecimiento de otros productos, como sucedía en 1441 cuando la duquesa de Alba obtenía licencia para abastecer a la ciudad con sus vacas ${ }^{55}$.

La intervención directa de los nobles en la gestión del abastecimiento a la ciudad de Burgos, solicitando la compra de los productos de sus villas, supuso am-

General de Simancas. Se trata de una respuesta a la apelación que la viuda de Pedro de Velasco habría interpuesto por la sentencia dictada sobre los maravedíes que debía su marido por el arrendamiento de las rentas en 1501, AGS, CCA, Pueblos, leg. 4.1., f. 249.

49. La participación de la nobleza en el suministro urbano ha sido examinada en Sebastián Moreno 2017c. Si bien este trabajo contiene una bibliografía actualizada en lo referente al abastecimiento urbano a la que remitimos, conviene señalar aquí al menos los siguientes trabajos, fundamentales para el ámbito burgalés: Bonachía Hernando 1992; Casado Alonso 1987, 1991; Guerrero Navarrete 1986a, pp. 325-370, 2009.

50. Casado Alonso 1987, pp. 127-138. La página 129 incorpora además un mapa de la distribución geográfica de los viñedos. Guerrero Navarrete 1986a, pp. 335-338; Sebastián Moreno 2017b, pp. $148-156$.

51. AMB, LLAA, 1453, f. 52r; 1462, f. 97r.

52. AMB, LLAA, 1461, ff. 125rv y 127r; 1492, f., 182v; 1497, f., 138r; 1499, ff. 25r; 126rv; 127r.

53. AMB, LLAA, 1463, f. 34rv.

54. AMB, LLAA, 1486, f. 52r.

55. AMB, LLAA, 1441, f. $42 \mathrm{v}$. 
plias ventajas para este grupo social, ya que de manera general el concejo accedió a sus demandas, llegando incluso a obtener amplias ventajas en la comercialización de los productos, tales como monopolios. De este modo ocurría en noviembre de 1461 con el conde de Buendía, cuando el concejo no sólo accedía a sacar vino de su villa de Dueñas para abastecer a la ciudad, sino que le concedía el monopolio de venta hasta enero por un precio de 7,5 maravedíes la cántara ${ }^{56}$.

Si nos referimos a los Velasco, aunque se constata la compra de productos a muchas de sus villas, sólo conservamos un par de noticias que registran esa participación directa de los miembros de la casa señorial en el abastecimiento. La primera de ellas corresponde al año 1504 cuando, en medio de la coyuntura de crisis de cereal en la que se encontraba sumida la ciudad, los condestables vendieron al concejo cereales de sus villas de Medina de Pomar y Villalpando ${ }^{57}$. En concreto, en el caso de Medina de Pomar, el concejo compró 600 fanegas de trigo, 320 de éstas por 325 maravedíes cada fanega ${ }^{58}$, es decir, por el triple de la tasa regia ${ }^{59}$. En relación con esta noticia, es importante señalar cómo el concejo se preocupó de enviar a Medina de Pomar a dos agentes cercanos al entorno del condestable Bernardino Fernández de Velasco y, por consiguiente, con quienes la negociación sería más sencilla. Pedro de Camargo, morador en el barrio de Cantarranas y vecino del condestable ${ }^{60}$, y Antonio de Melgosa, tesorero del condestable ${ }^{61}$.

Por otro lado, en lo tocante al aprovisionamiento de vino, mencionado en la segunda noticia, parece que, en 1506, debido al necesario avituallamiento que la ciudad requería con motivo de la visita de Juana I y Felipe el Hermoso, María de Velasco, hija del II conde de Haro, y por aquel entonces duquesa de Alburquerque y Roa, llegaba a un acuerdo con Burgos para entregar a la ciudad cuatro mil cántaras de vino desde su villa de Roa ${ }^{62}$. En relación con este asunto, se generará

56. AMB, LLAA, 1461, ff. 125rv; 126rv y $127 \mathrm{r}$.

57. AMB, LLAA, 1504, f. 64r. La parquedad de la información contenida en las actas municipales burgalesas, así como la ausencia de documentación municipal para la villa de Medina de Pomar, y especialmente de fuentes contables para la casa de Velasco, nos impiden profundizar para las fechas aquí mencionadas acerca de la procedencia de estos productos señoriales como pudo ser el cobro de rentas señoriales en especie. Los primeros registros de este tipo que se conservan para la casa de Velasco los hemos documentado para los años de 1527 y 1528 , conservados en el fondo de Frías bajo el título de "Relaciones de las rentas de varios lugares del condestable, cuentas particulares de la Casa de Velasco, personas que comían de la despensa del condestable e inventario de ropas y de los criados a quienes pagaba el contador Brizuela"; AHNOB, FRÍAS, c.93, d. 1-7.

58. AMB, LLAA, 1504 , f. $127 \mathrm{v}$.

59. Sebastián Moreno 2017b, p. 167.

60. AMB, LLAA, 1504, f. 64r.

61. En 1507 Antonio de Melgosa entró a formar parte del regimiento burgalés al ser elegido procurador mayor, cargo que ocupó los años 1508, 1509 y 1512, cuando en fue designado regidor. Durante estos años mantuvo su servicio a la casa de Velasco como tesorero del I duque de Frías. Tras el fallecimiento del I duque de Frías, Melgosa siguió sirviendo a la casa de Velasco como mayordomo del II duque de Frías. AMB, LLAA, 1507, f. 184v y 1512, ff. 144v-146v. Su designación en 1504 por parte del concejo burgalés como interlocutor preludia la labor de mediador que Melgosa desarrolló en los años siguientes como intermediario entre el concejo y los condestables. Una biografía de este personaje y de su servicio a la casa señorial puede encontrarse en: Montero Málaga 2017a, pp. 301-302.

62. "Los dichos señores rogaron e encargaron a los señores Alonso de Cartajena e Alonso de Lerma regidores que vayan a hablar con la señora duquesa de Roa que está que para que mande que en 
una cierta conflictividad entre la duquesa y el concejo, puesto que, a pesar de haberse comprometido, esta última no terminaba de entregar a la ciudad la cantidad acordada.

Además de estas dos breves noticias, otros documentos remiten a la comercialización de los productos procedentes de las villas del señorío nobiliario en la ciudad y al intento de los condestables por conseguir exenciones fiscales al respecto. En 1489 la villa de Medina de Pomar presentaba una demanda al concejo burgalés, por la que se quejaba del portazgo elevado que se cobraba a sus vecinos ${ }^{63}$. Situación que se repetía en $1494^{64}$ y $1495^{65}$. A diferencia de lo observado en el apartado anterior en relación con la percepción de los juros que la casa de Velasco tenía situados en las alcabalas de Burgos, regidores y alcaldes no se mostraron tan colaborativos en un primer momento a la hora de permitir a los vecinos medinenses la comercialización de sus productos en el mercado burgalés sin abonar los portazgos correspondientes a la ciudad, ya que esta medida suponía una merma de las rentas de la ciudad ${ }^{66}$. No obstante, en 1495, a pesar de las protestas suscitadas por parte de varios miembros del regimiento, Burgos concedía a los medinenses el mismo trato que a los burgaleses ${ }^{67}$. Así pues, desde 1495 y hasta 1498 , los vecinos de Medina de Pomar estuvieron exentos de pagar en la ciudad la renta de la barra, situación a la que la ciudad habría accedido a fin de evitar pleitos con el condestable, y en virtud de la antigua y buena vecindad que tenían con él ${ }^{68}$.

La medida adoptada por el concejo no debe entenderse solamente como uno más de los servicios que la ciudad prestó a los condestables por las buenas relaciones que mantenía con los Velasco, sino que hay que tener en cuenta otros incen-

lo que se obligaron los de su villa de Roa de dar a esta çibdad quatro mil cantaras de vino que lo cumple e le digan lo que les paresçiese". AMB, LLAA, 1506, f. 190v.

63. "Por que los vesynos de las villas de Medina de Pomar e Vriuiesca se quexan que lleban portadgos demasyados contra sus libertades e privillegios". AMB, LLAA, 1489, f. 172v.

64. "Entró en el ayuntamiento un onbre que se llamo Juan Orense Ferro vesyno de la villa de Medina de Pomar e presentó una carta mensajera por la qual la dicha villa se quexa dysiendo que ban contra su priuyllejo que la dicha villa tyene acerca de la barra de dicha çibdad que les lleban demasyado de lo que deben. Pide que lo manden remediar". AMB, LLAA, 1494, ff. 133v-134r.

65. "Por quanto los vesinos de Medina de Pomar se quexaron que los lleban el portadgo e la varra. Dieron cargo para lo ver a los señores alcalde del corregidor e al liçençiado Diego González del Castillo". AMB, LLAA, 1495, f. 50v.

66. Acerca de los conflictos provocados por el cobro de la barra a los mercaderes foráneos, véase: González Mínguez, 1985 y Sebastián Moreno 2017a, pp. 222-229. Para la renta de la barra: Pardos Martínez, 1982.

67. "Los dichos señores fablaron e platicaron sobre el debate e diferençia que tienen con la villa de Medina sobre el portadgo e varra por que los vesinos de la dicha villa mostraron pribillegio por ende non son obligados a pagar e por quanto por saber la verdad dieron cargo al bachiller Gomes de Madrid alcalde por el corregidor e al liçençiado Diego González del Castillo regidor desta çibdad los quales dixeron que auian visto el dicho pribillegio e por el paresçia que non eran obligados e por se quitar de pleitos e diferençias auian asentado que pagaran varra e portadgos segund e como los vesynos de la çibdad". AMB, LLAA, 1495, f. 121rv. Este documento ya ha sido citado en: Sebastián Moreno 2017 a, p. 228.

68. AGS, CRC, leg. 206, d. 1, f. 3. 
tivos económicos, particularmente, el mayor flujo de abastecimiento a la ciudad desde estas villas, que se vería favorecido por la exención fiscal ${ }^{69}$.

Por otra parte, es necesario considerar que, a pesar de las desventajas económicas que estos acuerdos con la nobleza podían suponer para la ciudad, representaban un claro beneficio político, ya que la ciudad veía en estas concesiones un mecanismo desde el que granjearse un posible favor futuro de los poderosos, estableciendo así una dinámica colaborativa con los mismos ${ }^{70}$.

2.2. La presencia nobiliaria en las rutas comerciales del norte: la cooperación con los mercaderes burgaleses

Desde mediados del siglo XIV los Velasco iniciaron una hábil política de expansión territorial con el fin de garantizar al linaje el dominio de zonas geográficas con un amplio valor estratégico que les permitiese extraer beneficios de diversa índole ${ }^{71}$. De este modo, los sucesivos cabezas del linaje fueron adquiriendo solares, casas fuertes, torres y puentes, que asegurasen la presencia del linaje en las principales rutas que, atravesando el territorio burgalés, unían la meseta con los puertos del Cantábrico como Laredo, Santander o Bilbao ${ }^{72}$. A lo largo de estos territorios, el control de estos enclaves representaba la materialización física del poder de los Velasco, eran la manifestación de su autoridad y presencia física sobre un determinado espacio. Sin embargo, más allá de lo que representó el control de dichos elementos arquitectónicos para el linaje en términos del ejercicio del poder señorial, gestión administrativa del señorío o representación identitaria del linaje $\mathrm{e}^{73}$, nos interesa destacar aquí fundamentalmente el interés económico que estos enclaves suponían.

Sobre todo, los titulares del linaje entendieron la adquisición de casas fuertes o torres como el mejor mecanismo para controlar el acceso a recursos como el vino o cereal. De ahí, por ejemplo, la expansión por el territorio riojano y la zona de La Bureba, pero también para fiscalizar el tránsito de hombres y mercancías que recorrían estas rutas. De este modo se garantizaban el cobro de derechos aduane-

69. Sebastián Moreno 2017a, p. 228.

70. También lo entiende así Sebastián Moreno 2017b, p. 167.

71. Sobre la expansión territorial del linaje véase González Crespo 1981; Moreno Ollero 2014 y Paulino Montero 2017, pp. 100-129.

72. Acerca de la presencia comercial de los Velasco en la zona de las Cuatro Villas de la Mar y los conflictos que generó en relación con la ruta que unía Burgos con Ladero y con Bilbao, territorio en el que los condestables tenían situados numerosos intereses, véase: Añíbarro Rodríguez 2013.

73. Son múltiples los significados a los que responden estos enclaves dentro de la lógica de expansión territorial del linaje. En este sentido, Elena Paulino remitía a las distintas espacialidades del poder que se generaban en torno a los mismos. Así, estos elementos deben ser entendidos dentro de una amplia estrategia territorial que englobaría, "no sólo el control militar, sino el de los recursos, el dominio sobre población, la creación y difusión de una imagen poderosa y prestigiosa del linaje y la organización y articulación del señorío en todos los niveles: administrativo, político, religioso [...], que genera distintas espacialidades del poder"; Paulino Montero 2013, pp. 1180. Además, en su tesis doctoral la autora citada analiza el papel que las torres y fortalezas adquieren en la administración territorial del señorío y en el desarrollo de la conciencia familiar; Paulino Montero 2015, pp. 458-483. 
ros mediante el control de portazgos, pontazgos, o incluso de barcajes, ya que, por ejemplo, desde el siglo XIV y hasta 1510 los Velasco controlaban el barco de Treto, cercano a Colindres y único medio de cruzar el río Ason si se utilizaba ese camino para ir de Santander hacia Laredo y viceversa ${ }^{74}$.

En este sentido, el control de enclaves estratégicos que conectasen con los puertos de la costa cantábrica en las actuales provincias de Vizcaya y Cantabria resultó una de las prioridades del linaje. Además, al respecto de esta cuestión es necesario señalar cómo desde mediados del siglo XV los Velasco habían manifestado interés por los diezmos de la mar, impuesto recaudado en la costa cantábrica sobre las mercancías que se importaban o exportaban por vía marítima que suponía el pago aproximado del 10\% del valor de las mercancías. Se trataba de una de las rentas más ricas de la Corona de Castilla que, a través de toda una serie de mercedes regias, fue enajenada íntegramente en 1469 en manos de los Velasco ${ }^{75}$. De este modo, los Velasco se hacían con el control de una renta por la que terminaron percibiendo más de dos millones de maravedíes anuales ${ }^{76}$. Así se explica el interés del linaje en la zona y el intento de control de enclaves estratégicos en la recaudación de dicho impuesto, como enseguida veremos para el caso vasco.

La expansión por la costa cantábrica correspondió fundamentalmente a Pedro (I) Fernández de Velasco a mediados del siglo XIV, que adquirió propiedades en Laredo y los territorios colindantes de Sámano y Ampuero. Esta labor fue continuada por Juan Fernández de Velasco y Pedro (II) Fernández de Velasco, a través de los que se reforzó la presencia del linaje en el valle de Villaverde o las Encartaciones, zona en la que los Velasco permanentemente trataron de adquirir Balmaseda, un enclave de un enorme valor estratégico en la recaudación de las alcabalas provenientes del tráfico de mercancías hacia Bilbao ${ }^{77}$. Asimismo, Juan Fernández de Velasco y su hijo el "Buen conde de Haro" se preocuparon por controlar el acceso a los puertos de Vizcaya tratando de adquirir enclaves en la ría del Nervión como Baracaldo y Luchana, villa esta última en la que disponían de varias torres ${ }^{78}$ y de una barca a la que se debía recurrir si se quería cruzar el rio Asua ${ }^{79}$. Al margen del

74. Álvarez Llopis, Blanco Campos 1999, p. 504.

75. Acerca del control de los diezmos de la mar por los Velasco véase: Díez de Salazar 1983; Franco Silva 1996, pp. 255-284; Pérez Bustamante 1983, pp. 355-375 y Salas Almela 2016. También fundamental para el estudio de los diezmos de la mar resultan los trabajos de Rubio Martínez 2008 y Vítores Casado 2001. Asimismo, para el periodo moderno y el territorio de Guipúzcoa véase: Truchuelo García, 2004.

76. Ladero Quesada 1972, pp. 124-125.

77. Así lo señalaba Dacosta Martínez 2003, p. 133.

78. No es nuestra intención detallar aquí los hitos del proceso expansionista del linaje en este territorio, pues consideramos que esta cuestión ha sido ampliamente abordada. En este sentido, remitimos a la tesis doctoral de Elena Paulino, no sólo por ser el trabajo más reciente sobre esta cuestión e incorporar una abundante bibliografía al respecto, sino por presentar el fenómeno de manera general atendiendo a una amplia cronología; Paulino Montero 2015, pp. 100-129. Además, concretamente para el caso de Cantabria véase: Muñoz Jiménez 2000, pp.17-30; 2011, pp.79-92; Pereyra Alza 2014. Finalmente, para la presencia del linaje en el territorio vasco; Dacosta Martínez 2003, pp. 127-143.

79. Por este pasaje los Velasco en 1509 los Velasco cobraban una blanca. Ese año los titulares del linaje pleitearon además con los vecinos comarcanos por el deseo de éstos de poner más barcas; AGS, CRC, leg. 659, d. 5. 


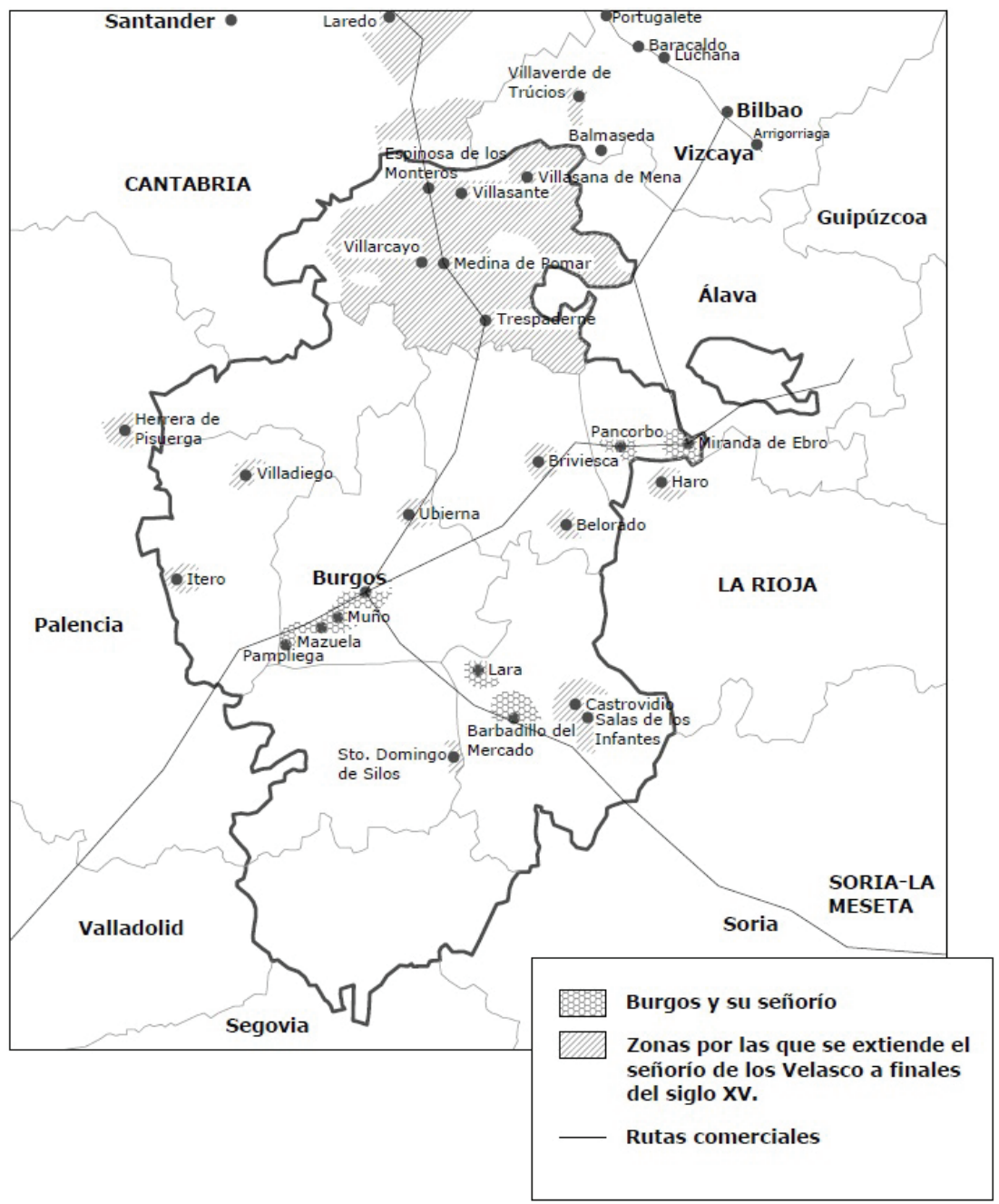

Mapa 1. Principales rutas comerciales que atraviesan el señorío de Burgos y de los Velasco a finales de la Edad Media ${ }^{80}$.

interés que adquieren estos lugares en relación con el comercio, no queremos dejar de señalar el valor que también pudieron tener para el linaje con motivo del acceso a materias primas como el hierro ${ }^{81}$.

80. Un mapa similar puede encontrarse en Montero Málaga 2014, p. 370.

81. Pedro (II) Fernández de Velasco había recibido de Pedro López de Ayala las herrerías de Luchana y Baracaldo, que se incorporarían al mayorazgo del primogénito. Véase el testamento del I conde de Haro; Porres Fernández 2009, p. 174. 
La importancia que alcanzó el linaje de Velasco durante los reinados de Juan II y Enrique IV en el territorio vizcaíno es de sobra conocida. La labor del linaje en Vizcaya no sólo se limitó a adquirir solares o edificar torres y casas fuertes, sino que además contaron con una amplia red de parientes, amigos y clientes, que les brindaron en muchas ocasiones una excusa perfecta para reforzar su presencia en este territorio, además de servir de apoyo en los diversos enfrentamientos que durante el siglo XV los titulares de la casa señorial mantuvieron en la zona con otros linajes, como ocurrió en 1421, año en el que los Velasco se enfrentaron al infante Juan de Aragón por el dominio sobre ciertos lugares de la merindad de Castilla Vieja $^{82}$ o como tuvo lugar en 1471 en la batalla de Munguía que enfrentó a las casas de Manrique y Velasco ${ }^{83}$. Sin embargo, nos interesa detenernos ahora en el interés del linaje por este territorio en tiempos de los Reyes Católicos debido a su relación con el concejo del Arlanzón y con algunos de los hombres de negocios burgaleses.

Aunque inconexas, la documentación arroja algunas noticias que nos permiten conjeturar acerca de las dinámicas cooperativas que en esta zona se habrían establecido entre los miembros de la casa señorial y los agentes burgaleses en base al aprovechamiento conjunto de los beneficios derivados de los flujos comerciales que tuvieron lugar en la zona y en relación con los diezmos de la mar. No se trata aquí de examinar detalladamente el proceso de administración de esta renta por parte de la casa de Velasco, sino de ofrecer algunos indicios que permiten señalar cómo, en este proceso, los condestables sin duda habrían optado por gestionar los diezmos de la mar de manera pactada con los mercaderes burgaleses. Esta vía, como acierta a señalar Salas Almela, no sólo fue una consecuencia natural de la expansión geográfica de ambas agencias, sino sobre todo fruto de un equilibrio de fuerzas, en el que los Velasco habrían tratado de evitar posibles conflictos con aquellos que debían de tributar a la vez que afianzaban su posición política en Burgos ${ }^{84}$. En este sentido, es necesario considerar cómo precisamente a partir de 1470, con la jefatura del II conde de Haro, Pedro (III) Fernández de Velasco, y frente a la política expansionista de sus antecesores, el interés de los titulares del linaje se concentró en Burgos, que se convirtió en el centro políticoadministrativo del señorío ${ }^{85}$. Así, por ejemplo, en 1503, en el momento en el que el condestable acordaba conjuntamente con el Consulado de la Mar de Burgos los precios de ciertas mercancías ${ }^{86}$, contaba con varios miembros de su clientela

82. Montero Málaga 2017a, p. 485. También González Crespo 1981, p. 297, Muñoz Gómez 2016, pp. 357-361 y Dacosta Martínez 2003, pp. 129-131.

83. Remitimos aquí a Dacosta Martínez 2003, pp. 139-140. Asimismo, este episodio ha sido examinado en Franco Silva 2006b, pp. 56-66 y Montero Málaga 2017a, pp. 505-508.

84. Salas Almela 2016, pp. 406 y 411.

85. Montero Málaga 2017a, pp. 500-538.

86. Fundada en 1494, esta institución jurídico-mercantil agrupó a los mercaderes más importantes de Castilla. Entre sus múltiples funciones, además de organizar el comercio exterior y proteger los intereses mercantiles burgaleses, el Consulado tenía capacidad jurídica para controlar y vigilar las transacciones comerciales; dirimir pleitos, no sólo entre sus miembros sino también del resto de mercaderes castellanos; establecer acuerdos, etc. Sobre esta institución y sus competencias véase: Basas 
en el regimiento, caso del alcalde Antonio Sarmiento, acostado de la duquesa de Frías, o del escribano mayor Gonzalo de Cartagena, maestresala del condestable ${ }^{87}$.

El primero de los inicios que apuntan a una dinámica cooperativa entre ambas agencias lo encontramos en 1480, cuando los oficiales concejiles burgaleses, junto con algunos miembros de la Universidad de Mercaderes y Consulado de la Mar de Burgos, mantuvieron acuerdos en torno a los diezmos de la mar. Esta información la deducimos a través de dos noticias: la primera se encuentra inserta en las actas municipales de 1480, que registran cómo los mercaderes Pedro Pardo, en nombre del difunto prior Alonso Fernández de Cisneros, y Pedro de Miranda, en nombre del cónsul Pedro de Miranda, junto con el escribano mayor Fernando de Covarrubias, debían nombrar personas que entiendan con los manyficos sennores condestable de Castilla e condesa de Haro sobre rasón de la renta de los diesmos ${ }^{88}$. La segunda procede del "Inventario de los fondos del Archivo del Consulado del Mar" realizado en torno a 1814. El folio 8v de este inventario de 122 folios, en el que se recogen hasta 52 legajos, incluye información acerca de la existencia del siguiente documento que, si bien no se ha conservado, sin duda remite al mismo asunto que quedó reflejado en la documentación municipal; "Combenios, ajustes y contratos hechos ante el muy Magnifico y Noble Señor Don Pedro Fernández de Velasco Condestable de Castilla Conde de Aro de la una Parte, y de la otra la Unibersidad de Mercaderes de esta Ciudad en razón de los Diezmos de la Mar que de sus mercaderías havian de satisfacer al dicho Señor. Contienen igualmente otros contratos unos firmados del dicho señor y de dichos mercaderes que no dejan de ser de comercio. Año 1480" 89 .

Muy probablemente estos acuerdos habrían estado destinados a establecer conjuntamente las cuantías a percibir dicho importe. Así sucedía en 1503, cuando el prior y cónsules de la Universidad de Mercaderes de Burgos (Andrés de Pesquera, Juan de Miranda y Álvaro Pardo) fijaron junto con Juliana Ángela de Velasco, quien actuaba en nombre de su padre Bernardino Fernández de Velasco, un arancel en el que se estipulaban las tarifas que se iban a aplicar en el cobro del diezmo en función de las mercancías ${ }^{90}$. Posteriormente, este arancel trató de imponerse en Guipúzcoa dando lugar a un largo pleito ${ }^{91}$. En este sentido, cabría suponer que

Fernández 1994; Bonachía Hernando 1994; Casado Alonso, 2002 y 2008; González Arce 2009 y 2010. Imprescindibles para el estudio del comercio burgalés resultan los trabajos del profesor Hilario Casado Alonso y Betsabé Caunedo del Potro, algunos de ellos: Casado Alonso 1994, 1995, 2001, 2003, 2012 y 2015; Caunedo del Potro, 1981, 1983, 1990, 1998 y 2006.

87. Montero Málaga 2017a, pp. 273-276 y 307-308.

88. AMB, LLAA, 1480, f. 24v-25r.

89. ADPBU, CM, 793, f. 8v.

90. AGS, CMC, Segunda Época, leg. 161. Esta información también se encontraría contenida en uno de los legajos de Frías, según ha documentado Luis Salas Almela, AHNOB, FRIAS, c. 551, d. 26 "Nómina de los precios que se pagan e acostumbran a pagar al señor condestable". Salas Almela, 2016, p. 406.

91. Díez de Salazar 1983, pp. 25 y 65. Salas Almela 2016 y Susana Truchuelo 2004. A propósito de esta cuestión es interesante señalar cómo el concejo de San Sebastián pleiteó en 1504 con Bernardino Fernández de Velasco acerca del pago del diezmo, aludiendo a que desde 1489 poseía un privilegio que le eximia del pago de tributos hasta 1509; ARChVa, Ejecutorias, c. 190, exp. 11. 
los burgaleses buscasen en estos acuerdos un beneficio fiscal. En este sentido, tal y como señala Salas Almela, la propia cédula de creación del Consulado sería un reflejo del intento de cooperación que habrían llevado a cabo los mercaderes burgaleses y el condestable, puesto que en ella se preveían ya ventajas fiscales en relación con los diezmos de la mar y los miembros del Consulado ${ }^{92}$. Así parece corroborarlo una noticia contenida en las actas municipales de Vitoria. En el año de 1500 , los mercaderes vitorianos se quejaban al concejo de esta ciudad de que pagaban más diezmo que los mercaderes de Burgos ${ }^{93}$. Asimismo, conviene mencionar cómo entre 1511 y 1512, el prior del Consulado fue el ya citado Antonio de Melgosa $^{94}$, tesorero de Bernardino Fernández de Velasco ${ }^{95}$.

Otra noticia que remite a la posible cooperación entre mercaderes y Velasco por el diezmo de la mar se encuentra contenida en el Archivo Histórico de Bilbao. Nos referimos al mandamiento que en febrero de 1499 realizan los Reyes Católicos, a petición del concejo de Bilbao y tras las quejas expresadas por el mismo, al corregidor de Vizcaya para que informase acerca del intento del I duque de Frías de fundar una villa en Baracaldo ${ }^{96}$.

Ya hemos comentado cómo desde mediados del siglo XV los sucesivos cabezas del linaje de Velasco trataron de hacerse con el control de puntos estratégicos en la ría del Nervión como Luchana, que les garantizase el acceso a la fiscalización de las mercancías que transitaban por esas rutas. En esta línea se inscribe el intento de Bernardino Fernández de Velasco por adquirir y edificar torres en Baracaldo, pese al frontal rechazo que mostró el concejo de Bilbao, tal y como se recoge en el documento de 1499.

El dominio de los Velasco sobre Baracaldo suponía para el concejo de Bilbao la pérdida de sus privilegios en el control de la compraventa de mercancías, por lo que trató de evitar la creación de estos posibles enclaves de distribución comercial ${ }^{97}$. Como se recoge en la incitativa regia de 1499, desde tiempos de Juan I de Castilla, Bilbao poseía el privilegio de ser el único centro en el que podía tener lugar la venta y reventa de mercancías en un radio que iba desde Bilbao fasta Araeta nin fasta Varacaldo nin fasta Çamudio ${ }^{98}$. Por consiguiente, el dominio de los condestables sobre Baracaldo, y la venta y reventa de mercancías que estaba

92. Salas Almela 2016, p. 412.

93. "Este dicho día de parte de los mercaderes se dijo que el sennor condestable manda que los mercaderes de la çibdad en el diesmo paguen más que los de Burgos e es menester que la çibdad escriba cartas para su sennoría las que menester fuese con una persona dellos que quieran enbiar"; AMV, Actas Municipales, vol. V (1496-1502), f. 131r.

94. Vid. Nota

95. González Arce 2010, p. 168.

96. Citamos a continuación por la transcripción del documento que se encuentra contenida en Enríquez Fernández, Hidalgo de Cisneros Amestoy, Martínez Lahidalga 1999, pp. 781-782. Documento 240 "Incitativa al corregidor para que informe de las compras y ventas que se hacen en las poblaciones comarcanas a Bilbao, así como del intento del Condestable de fundar una villa en Baracaldo, todo ello en contravención de los privilegios de Bilbao".

97. García Fernández 2013, p. 102.

98. Citamos por la transcripción contenida en Enríquez Fernández, Hidalgo de Cisneros Amestoy, Martínez Lahidalga 1999, p. 781. 
teniendo ya lugar allí, contradecía el privilegio de Bilbao, que además argumentaba cómo esto suponía un encarecimiento de las mercancías, [...] donde comiençan a vender e revender e conprar las cosas en ellos antes/ que lleguen a la dicha villa e dis que despues los venden a los vezinos della, a cuya cabsa se encaresçen los mantenimientos $[\ldots]^{99}$.

Esta situación era consentida por los propios mercaderes, pues el condestable tenía a todos los mercaderos debaxo de su mano a cabsa de los diezmos de la $m a r^{100}$. En este sentido, parece probable que el documento haga referencia a agentes ajenos a la villa de Bilbao, probablemente a los burgaleses, más proclives a la cooperación con sus vecinos los condestables, sobre todo ciertas familias con las que los Velasco mantenían por estas fechas relaciones comerciales. Sirva de muestra el linaje urbano de los Soria, miembros del regimiento burgalés desde finales del siglo XV en donde actuaron como regidores y alcaldes, además de destacados miembros del comercio internacional, que en 1480 actuaban como banqueros de los condestables recibiendo un depósito de 200.000 maravedíes por la boda de Ana de Velasco ${ }^{101}$, o los Pardo, también mercaderes, con los que tanto Pedro (II) Fernández de Velasco como su nieto el conde de Nieva mantuvieron acuerdos comerciales ${ }^{102}$. Además de otros mercaderes con los que los condes de Haro habrían sostenido tratos con anterioridad, según se contiene en el testamento del I conde de Haro, en el que se alude a los préstamos por valor de 200. 000 maravedíes que en 1457 le habrían hecho a Pedro (II) Fernández de Velasco çiertos mercaderes de Burgos $^{103}$.

La alusión a los diezmos de la mar aquí y a la posible cooperación con los mercaderes, unido a las negociaciones ya mencionadas de los años ochenta y posteriores en torno a esta cuestión con agentes burgaleses, nos permiten suponer un posible acuerdo sostenido entre los condestables y los mercaderes burgaleses en torno al tráfico comercial. De tal modo que los condestables pudiesen haberse beneficiado del control de la carga y descarga de productos de mercancías en sus territorios, a los que atraían a los mercaderes a través de una posible reducción de la tasa impositiva del diezmo, que era menor para los mercaderes burgaleses según lo expresado por el concejo de Vitoria.

Este asunto debe ser puesto en relación con el nombramiento de Pedro (III) Fernández de Velasco en 1470 con poderes de virrey para vigilar la gobernación

99. Ibíd., p. 781. Una situación similar a la que esta noticia remite se documenta también para el caso de Santander, villa a la que debían pedir licencia los lugares cercanos a su bahía para cargar y descargar mercancías. En 1495 esta cuestión motivó un pleito entre el concejo de Santander y el condestable Bernardino Fernández de Velasco por los barcos de Treto, cuya titularidad, como sabemos, ostentaban los Velasco. Solórzano Telechea 2002, p. 309.

100. Transcripción de Enríquez Fernández, Hidalgo de Cisneros Amestoy, Martínez Lahidalga 1999, p. 781.

101. AGS, RGS, leg., junio de 1480, f. 305.

102. Como por ejemplo se observa en 1499, en relación con el pleito sostenido entre el conde de Nieva, Antonio de Velasco, y el mercader burgalés Juan Pardo, a propósito de deudas por la compra de unas mercancías que su padre, Sancho de Velasco, habría tramitado con dicho mercader. ARChVa, Ejecutorias, c. 139, exp. 9 .

103. Citamos por la transcripción de Alonso de Porres 2009, p. 173. 
de Vizcaya y Guipúzcoa, una designación que habría sido realizada por Enrique IV a petición de los mercaderes de Burgos, molestos por los problemas que durante esos años estaban causando a sus negocios Juan Alonso de Mújica en tierra, y Pedro de Avendaño con sus barcos en la mar ${ }^{104}$. Este episodio fue interpretado por Luis Suárez en el marco de "alguna clase de dirección y desarrollo de ese gran eje mercantil que significaba el enlace entre el patriciado burgalés y los transportistas que utilizaban la ría de Portugalete, puerta de acceso a las rutas del mar"105.

En suma, atendiendo a las noticias presentadas, parece factible considerar la existencia de una cooperación comercial entre los condestables y los hombres de negocios burgaleses basada en la coincidencia de intereses en la explotación del tráfico comercial de Vizcaya. Cuestión que por otra parte explicaría la ausencia de pleitos entre el Consulado y la casa señorial ${ }^{106}$. De este modo, tanto los agentes burgaleses como los miembros de la casa señorial se beneficiaron conjuntamente de esta cooperación económica, que además les facilitaba la competencia frente a terceros como los mercaderes bilbaínos.

Finalmente, es necesario señalar que, aunque sólo hemos sido capaces de documentar pequeños indicios de esta cooperación para la zona vasca, esta dinámica de actuación colaborativa muy probablemente también se hubiese exportado hacia otros territorios. Así, por ejemplo, en 1514 el concejo de Burgos prestaba apoyo a los Velasco ${ }^{107}$ en el contencioso que el linaje mantenía con los condes de Benavente por la villa de Cigales ${ }^{108}$. En este caso, la comunidad de intereses de la ciudad con la proyección territorial de los Velasco venía dada por las consecuencias que parecían estar teniendo para el abastecimiento de vino de Cigales a Burgos las actuaciones del conde de Benavente en la villa.

\section{A MOdo DE CONCLUSIÓN}

En definitiva, los ejemplos anteriormente examinados nos permiten afirmar la existencia de dinámicas cooperativas establecidas entre la casa de Velasco y la Caput Castellae en distintas áreas de la economía burgalesa. En este sentido, es posible constatar diferentes escalas en la cooperación tanto en el ámbito de la fiscalidad como del mercado urbano. En lo que respecta a la percepción de los privilegios que los titulares del linaje tenían asentados en Burgos, al facilitar el cobro de los maravedíes que los condestables tenían en estas rentas reales, el concejo cooperaba con la casa señorial. No obstante, se trataría de uno de los escalones más bajos dentro de esta dinámica, puesto que no se perseguiría un beneficio con-

104. Dacosta Martínez 2003, p. 140 y Franco Silva 2006b, pp. 56-58. Este nombramiento ha quedado registrado en un documento de agosto de 1470 en el que se anota cómo Enrique IV habría concedido ciertos poderes en Vizcaya a Pedro (III) Fernández de Velasco para su pacificación. Enríquez Fernández, Hidalgo de Cisneros Amestoy, Martínez Lahidalga 1999, p. 400.

105. Suárez Fernández 2002, p. 464.

106. Salas Almela 2016, p. 412.

107. AMB, LLAA, 1514, ff. 141r, 142r y 151r-152r.

108. Se trata de un pleito muy largo que se retrotrae al menos hasta 1512. La documentación al respecto se encuentra inserta en una ejecutoria del año 1591. AMB, HI, 3996. 
junto, aunque el concejo si obraría para favorecer el beneficio individual de los condestables.

Por el contrario, los datos examinados a propósito del establecimiento de acuerdos comerciales en la ruta hacia el Cantábrico demuestran un nivel de cooperación mayor, no sólo porque estas acciones requerían que ambas agencias trabajasen de manera conjunta sobre la base de la confluencia de intereses económicos, sino que de ello se derivó la persecución de un beneficio común, que se vio maximizado por esta cooperación. En este sentido, frente a la opción de la competencia por la proyección sobre determinados territorios en la franja que iba desde Burgos hasta los puertos del Cantábrico, en la que tanto la ciudad como la casa señorial tenían intereses económicos por lo que se refiere al control de hombres, tierras y recursos de diversa índole, estas agencias optaron por establecer un modelo de relaciones cooperativo en torno a esa confluencia de intereses de la que ambas se verían beneficiadas, especialmente frente a terceros competidores.

\section{BIBLIOGRAFÍA CITADA}

Alonso García, David (2006), "Poder financiero y arrendadores de rentas reales en Castilla a principios de la Edad Moderna", Cuadernos de Historia Moderna, 31, pp. 117-138.

Álvarez Álvarez, César (1999) "Linajes nobiliarios y oligarquías urbanas en León”, en VV. AA (1999), La nobleza peninsular en la Edad Media. VI Congreso de estudios medievales, León: Fundación Sánchez Albornoz, pp. 35-65.

Álvarez Borge, Ignacio (1996), Poder y relaciones sociales en Castilla en la Edad Media. Los territorios entre el Arlanzón y el Duero en los siglos X al XIV, Salamanca: Junta de Castilla y León.

Álvarez Borge, Ignacio (1997) "Nobleza y señoríos en Castilla la vieja meridional a mediados del siglo XIV”, Cuadernos de Investigación Histórica, 21, pp. 55-117.

Álvarez Borge, Ignacio (2001), "Los señoríos de los Rojas en 1352”, en Estepa Díez, Carlos; Jular Pérez-Alfaro, Cristina (coords.), Los señoríos de Behetría, Madrid: Consejo Superior de Investigaciones Científicas, pp. 73-144.

Álvarez Borge, Ignacio (2010), "Vasallos, oficiales, clientes y parientes. Sobre la jerarquía y las relaciones internobiliarias en la Castilla medieval (c.11001350). Una aproximación a partir de las fuentes documentales”, Hispania, 235, pp. 359-390.

Álvarez Borge, Ignacio (2016), "Patrimonio, renta y poder de la nobleza bajomedieval peninsular", en Discurso, memoria y representación. La nobleza peninsular en la Baja Edad Media, XLII Semana de Estudios Medievales de Estella, 21-24 de julio de 2015, Pamplona, pp. 83-141.

Álvarez Llopis, Elisa; Blanco Campos, Emma (1999), "Las vías de comunicación en Cantabria en la Edad Media", en I Encuentro de Historia de Cantabria. Actas del encuentro celebrado en Santander los días 16 a 19 de diciembre de 1996, Santander: Universidad de Cantabria, t. I, pp. 491-523. 
Álvarez Nogal, César (2009), “Oferta y demanda de deuda pública en Castilla. Juros de alcabalas (1540-1740)”, Estudios de Historia Económica, 55, pp. 142-163.

Añíbarro Rodríguez, Javier (2013), Las Cuatro Villas de la Costa de la Mar en la Edad Media. Conflictos jurisdiccionales y comerciales, Santander (Tesis doctoral leída en la Universidad de Cantabria).

Asenjo González, María (eds.), (2009), Oligarchy and patronage in late medieval spanish urban society. Studies in european urban history (1100-1800), Turnhout: Brepols.

Asenjo González, María (eds.), (2013), Urban elites and aristocratic behaviour in the Spanish kingdoms and the end of the Middle Ages, Turnhout: Brepols.

Basas Fernández, Manuel (1994), El consulado de Burgos en el siglo XVI, Burgos: Diputación Provincial.

Beceiro Pita, Isabel (1998), El condado de Benavente en el siglo XV, Benavente: Centro de Estudios Benaventano.

Beceiro Pita, Isabel; Córdoba de la Llave, Ricardo (1990), Parentesco, poder y mentalidad. La nobleza castellana, siglos XII-XV, Madrid: Consejo Superior de Investigaciones Científicas.

Bonachía Hernando, Juan Antonio (1987), El concejo de Burgos en la Baja Edad Media (1345-1426), Valladolid: Universidad de Valladolid. Secretario de Publicaciones.

Bonachía Hernando, Juan Antonio (1988), El Señorío de Burgos durante la Baja Edad Media (1255-1508), Valladolid: Secretario de Publicaciones.

Bonachía Hernando, Juan Antonio (1992), “Abastecimiento urbano, mercado local y control municipal: la provisión y comercialización de la carne en Burgos (siglo XV)", Espacio, tiempo y forma. Serie III, historia medieval, 5, pp. 85-162.

Bonachía Hernando, Juan Antonio (1994), "La ciudad de Burgos en la época del Consulado (apuntes para un esquema de historia urbana)", en Actas del V Centenario del Consulado de Burgos (1494-1994), Burgos: Diputación Provincial de Burgos, pp. 69-145.

Bello León, Juan Manuel (2014), "Los beneficios de la Hacienda Real. Privilegios, situados y libranzas en el almojarifazgo mayor de Sevilla a finales del siglo XV. Algunos datos cuantitativos", en Borrero Fernández, María de las Mercedes; Carrasco Pérez, Juan; Peinado Santaella, Rafael (coords.), Agentes de los sistemas fiscales en Andalucía y los reinos hispánicos (siglos XIII-XVII). Un modelo comparativo, Madrid: Instituto de Estudios Fiscales, pp. 211-239.

Cabrera Muñoz, Enrique (1977), El condado de Benalcázar (1444-1518). Aproximación al estudio del régimen señorial en la Baja Edad Media, Córdoba: Monte Piedad y Caja de Ahorros.

Cabrera Sánchez, Margarita (1998), Nobleza, oligarquía y poder en Córdoba al final del siglo $X V$, Córdoba: Universidad de Córdoba-Caja Sur.

Casado Alonso, Hilario (1987), Señores, mercaderes y campesinos: la comarca de Burgos a finales de la Edad Media, Valladolid: Junta de Castilla y León. 
Casado Alonso, Hilario (1991), "Producción agraria, precios y coyuntura económica en las diócesis de Burgos y Palencia a fines de la Edad Media", Studia historica. Historia medieval, 9, pp. 67-109.

Casado Alonso, Hilario (1994), "El comercio internacional burgalés en los siglos XV y XVI", en VV.AA., Actas del V Centenario del Consulado de Burgos, vol. I, Burgos: Diputación Provincial, pp. 175-247.

Casado Alonso, Hilario (1995), Castilla y Europa. Comercio y mercaderes en los siglos XIV, XV y XVI, Burgos: Diputación provincial.

Casado Alonso, Hilario (2001), "El comercio burgalés y la estructuración del espacio económico español a fines de la Edad Media", en VV.AA., Itinerarios medievales e identidad hispánica: XXVII Semana de Estudios Medievales, Estella 17 a 21 de julio de 2000, Pamplona: Gobierno de Navarra, pp. 329-356.

Casado Alonso, Hilario (2002), "Los seguros marítimos de Burgos. Observatorio del comercio internacional portugués en el siglo XVI", Revista da Faculdade de Letras. História. Porto. III Série, vol. IV, pp. 213-242.

Casado Alonso, Hilario (2003), El triunfo de Mercurio. La presencia castellana en Europa (siglos XV-XVI), Burgos: Cajacírculo.

Casado Alonso, Hilario (2008), "Los flujos de información en las redes comerciales castellanas de los siglos XV y XVI", Investigaciones de Historia Económica, 10, pp. 25-68.

Casado Alonso, Hilario (2012), "Crecimiento económico, redes de comercio y fiscalidad en Castilla a fines de la Edad Media" en Bonachía Hernando, Jun Antonio; Carvajal de la Vega, David (coords.), Los negocios del hombre: comercio y rentas en Castilla, siglos XV y XVI, Valladolid: Castilla Ediciones, 2012, pp. 17-35.

Casado Alonso, Hilario (2015), "Circuitos comerciales y flujos financieros en Castilla a fines de la Edad Media e inicios de la Modernidad", en VV.AA., Estados y mercados financieros en el Occidente cristiano (siglos XIII-XVI), Pamplona: Gobierno de Navarra, pp. 273-307.

Caunedo del Potro, Betsabé (1981), Mercaderes castellanos en el golfo de Vizcaya (1475-1492), Madrid (tesis doctoral leída en la Universidad Autónoma de Madrid). Online en: https://repositorio.uam.es/xmlui/handle/10486/7749. Consultado el 12 de enero de 2018.

Caunedo del Potro, Betsabé (1983), Mercaderes castellanos en el golfo de Vizcaya (1475-1492), Madrid: Universidad Autónoma de Madrid.

Caunedo del Potro, Betsabé (1990), "Mercaderes burgaleses en el tránsito a la modernidad: notas sobre el estado de la cuestión”, Hispania: Revista española de historia, 50, 175, pp. 809-826.

Caunedo del Potro, Betsabé (1998), "Factores burgaleses, ¿privilegiados o postergados?”, En la España Medieval, 21, pp. 97-114.

Caunedo del Potro, Betsabé (2006), "La disgregación de una rica hacienda: el ocaso mercantil de los descendientes de Diego de Soria. ¿Un problema político?”, Espacio, tiempo y forma. Serie III. Historia Medieval, 19, pp. 77-97. 
Carvajal de la Vega, David (2013), Crédito privado y deuda en Castilla (1480-1521), Valladolid (tesis doctoral leída en la Universidad Autónoma de Valladolid).

Carvajal de la Vega, David (2011), "Redes socioeconómicas y mercaderes castellanos a fines de la Edad Media e inicios de la Moderna", en Carvajal de la Vega, David; Añíbarro Rodríguez, Javier; Vítores Casado, Imanol (coords.), Redes sociales y económicas en el mundo bajomedieval, Valladolid: Castilla Ediciones, pp. 79-102.

Dacosta Martínez, Arsenio (2003), Los linajes de Bizkaia en la Baja Edad Media: Poder, Parentesco y Conflicto, Bilbao: Universidad del País Vasco, pp. 129-131.

Diago Hernando, Máximo (1991), “Arrendadores arandinos al servicio de los Reyes Católicos”, Historia, Instituciones y Documentos, 18, pp. 71-96.

Diago Hernando, Máximo (1992), "Estructuras familiares de la nobleza urbana en la Castilla bajomedieval: los doce linajes de Soria”, Studia Historica. Historia Medieval, 10, pp. 47-72.

Diago Hernando, Máximo (2007), "La participación de la nobleza en el gobierno de las ciudades europeas bajomedievales. Análisis comparativo", Anuario de Estudios Medievales, 37, 2, pp. 781-822.

Diago Hernando, Máximo (2009), "La proyección de las casas de la alta nobleza en las sociedades políticas regionales: el caso soriano a fines de la Edad Media", Anuario de Estudios Medievales, 39, 2, pp. 843-876.

Diago Hernando, Máximo (2014), "Intervencionismo de la alta nobleza en la vida política de las ciudades castellanas a fines de la Edad Media: los mariscales de Castilla en Soria", Edad Media: Revista de Historia, 15, pp. 245-271.

Díaz de Durana, José Ramón (1998), La lucha de bandos en el País Vasco: de los Parientes Mayores a la Hidalguía Universal. Guipúzcoa, de los bandos a la provincia, Bilbao: Universidad del País Vasco.

Díez de Salazar, Luis Miguel (1983), Diezmo viejo y seco o diezmo de la mar de Castilla (siglo XIII-XV), San Sebastián: Gráficas Eset.

Enríquez Fernández, Javier; Hidalgo de Cisneros Amestoy, Concepción; Martínez Lahidalga, Adela, (1999), Fuentes documentales medievales del País Vasco. Colección documental del Archivo Histórico de Bilbao (1473-1500), Donostia: Eusko Ikaskuntza.

Franco Silva, Alfonso (1996), "Los condestables de Castilla y la renta de los diezmos de la mar", en La fortuna y el poder. Estudios sobre las bases económicas de la aristocracia castellana (siglos XIV-XV), Cádiz: Universidad de Cádiz, pp. 465-499.

Franco Silva, Alfonso (1997), Señores y señoríos (siglos XIV-XVI), Jaén: Universidad de Jaén.

Franco Silva, Alfonso (2006a), "El gobierno y la administración de un señorío. El modelo de los Velasco (1368-1470)”, Mínguez Fernández, José María; Del Ser Quijano, Gregorio (coords.), La Península Ibérica en la Edad Media: treinta años después. Estudios dedicados a José Luis Martín, Salamanca: Universidad de Salamanca, pp. 137-142. 
Franco Silva, Alfonso (2006b), Entre los reinados de Enrique IV y Carlos V. Los condestables del linaje Velasco. (1461-1559), Jaén: Universidad de Jaén.

Franco Silva, Alfonso (2006c), Estudios sobre la nobleza y el régimen señorial en el reino de Castilla (siglo XIV-mediados del siglo XVI), Cádiz: Universidad de Cádiz.

García Fernández, Ernesto (2013), “Teorías y praxis política en el País Vasco a fines de la Edad Media: los gobiernos urbanos y los vecinos de la Tierra", Monsalvo Antón, José María (ed.), Sociedades urbanas y culturas políticas en la Baja Edad Media castellana, Salamanca: Universidad de Salamanca, pp. 71-123.

Gerbet, Marie Claude (1989), La nobleza en la Corona de Castilla: sus estructuras sociales en Extremadura (1454-1516), Cáceres: Institución cultural "El Broncense", Diputación Provincial de Cáceres.

González Arce, José Damián (2009), “La ventaja de llegar primero: estrategias en la pugna por la supremacía mercantil durante los inicios de los consulados de Burgos y Bilbao (1450-1515)", Miscelánea medieval murciana, 33, pp. 77-97.

González Arce, José Damián (2010), "La universidad de mercaderes de Burgos y el consulado castellano en Brujas durante el siglo XV", En la España Medieval, 33, pp. 161-202.

González Crespo, Esther (1986), "El patrimonio de los Velasco a través de "El libro de las Behetrías". Contribución al estudio de la fiscalidad señorial", Anиario de Estudios Medievales, 16, pp. 239-250.

González Mínguez, César (1985), “Algunos conflictos entre los mercaderes vitorianos y los arrendadores de la renta de la barra y portazgo de Burgos en el siglo XV", en VV.AA., La ciudad de Burgos. Actas del Congreso de Historia de Burgos: MC aniversario de la fundación de la ciudad 884-1984, Valladolid: Junta de Castilla y León, pp. 201-216.

Guerrero Navarrete, Yolanda (1986a), Organización y gobierno en Burgos durante el reinado de Enrique IV de Castilla. 1453-1476, Madrid: Universidad Autónoma de Madrid.

Guerrero Navarrete, Yolanda (1986b), "Fiscalidad regia y poder municipal en Burgos. 1453-1476”, En la España medieval, Homenaje a Claudio Sánchez Albornoz, 8, pp. 482-499.

Guerrero Navarrete, Yolanda (1989), “Consumo y comercialización de pescado en las ciudades castellanas de la Baja Edad Media”, en VV. AA., La pesca en la Edad Media, Murcia: Servicio de Publicaciones, Consejo Superior de Investigaciones Científicas, pp. 235-259.

Guerrero Navarrete, Yolanda (2017), "Ciudades de realengo y estrategias nobiliarias en la Castilla bajomedieval: el caso de Burgos y los Estúñiga”, en Jara Fuente, José Antonio (coord.), Discurso político y relaciones de poder: Ciudad, nobleza y monarquía en la Baja Edad Media, Madrid: Dykinson, pp. 291-326.

Guerrero Navarrete, Yolanda; Sánchez Benito, José María (1990), “La Corona y el poder municipal. Aproximación a su estudio a través de la elección a procu- 
radores de Cortes en Cuenca y Burgos en el siglo XV", en VV.AA. Las Cortes de Castilla y León, 1188-1988. Actas del congreso científico sobre las Cortes de Castilla y León, 26-30 de septiembre de 1988, Valladolid: Cortes de Castilla y León, pp. 381-399.

Jara Fuente, José Antonio (1997) "La nobilización de un concejo en el siglo XV: Cuenca y los Hurtado de Mendoza”, en González Jiménez, Manuel (ed.), La Península Ibérica en la era de los descubrimientos (1391-1492): Actas de las III Jornadas Hispano-Portuguesas de Historia Medieval. Sevilla, 25-30 de noviembre de 1991, Sevilla: Conserjería de Cultura, vol. II, pp. 1025-1034.

Jara Fuente, José Antonio (2013a), "Didáctica de las relaciones políticas ciudadnobleza en la Cuenca del siglo XV. Cerçada de muchos contrarios", Edad Media: Revista de Historia, 14, pp. 105-127.

Jara Fuente, José Antonio (2013b) "Disciplinando las relaciones políticas: ciudad y nobleza en el siglo XV”, en Monsalvo Antón José María (ed.), Sociedades urbanas y culturas políticas en la Baja Edad Media castellana, Salamanca: Universidad de Salamanca, pp. 165-231.

Jara Fuente, José Antonio (coord.), (2017), Discurso político y relaciones de poder: Ciudad, nobleza y monarquía en la Baja Edad Media, Madrid: Dykinson.

Jular Pérez-Alfaro, Cristina (2013), "Los solares de don Haly. Liderazgo y registro escrito de la Casa de Velasco en el siglo XIV", Stvdia Zamorensia, Segunda Etapa, vol. XII, pp. 57-87.

Ladero Quesada, Miguel Ángel (1972), La Hacienda Real de Castilla, La Laguna: Universidad de La Laguna.

Ladero Quesada, Miguel Ángel (1982), El siglo XV en Castilla. Fuentes de renta y política fiscal, Barcelona: Ariel.

Ladero Quesada, Miguel Ángel (1998), Los señores de Andalucía. Investigaciones sobre nobles y señorios en los siglos XIII al XV, Cádiz: Universidad de Cádiz.

Ladero Quesada, Miguel Ángel y Olivera Serrano, César (dirs.) (2016), Documentos sobre Enrique IV de Castilla y su tiempo, Madrid: Universidad Carlos III de Madrid, vol I.

Millán da Costa, Adelaide; Jara Fuente, José Antonio (eds.), (2016), Conflicto Político: Lucha y cooperación. Ciudad y nobleza en Portugal y Castilla en la Baja Edad Media, Lisboa: Instituto de Estudos Medievais.

Monsalvo Antón, José María (2008), "En torno a la cultura contractual de las élites urbanas: pactos y compromisos políticos (linajes, bandos de Salamanca, Ciudad Rodrigo y Alba de Tormes)", en Foronda François; Carrasco Manchado, Ana Isabel (dirs.), El contrato político en la Corona de Castilla. Cultura y sociedad políticas entre los siglos X al XVI, Madrid: Dykinson, pp. 159-209.

Monsalvo Antón, José María (2013) “Torres, tierras, linajes. Mentalidad social de los caballeros urbanos y de la élite dirigente en la Salamanca medieval (siglos XIII-XV)", en Monsalvo Antón, José María (ed.), Sociedades urbanas y culturas políticas en la Baja Edad Media castellana, Salamanca: Universidad de Salamanca, pp. 165-231. 
Montero Málaga, Alicia Inés (2012), El linaje de los Velasco y la ciudad de Burgos (1379-1520). Identidad y poder político, Madrid: La Ergástula.

Montero Málaga, Alicia Inés (2014), "Red urbana y red señorial: problemáticas de la expansión señorial de los Velasco en Burgos a finales de la Edad Media", Cunha, Ana, Pinto, Olimpia y De Olivera Martins, Raquel (coords.), Actas do I Encontro Ibérico de Jovens Investigadores em Estudos Medievais, Arqueologia, História e Património, Braga: Centro de Investigação Trandisciplinar, pp. 351-371.

Montero Málaga, Alicia Inés (2017a), Los nobles en la ciudad. La casa de Velasco y la ciudad de Burgos (1379-1520), Madrid (tesis doctoral leída en la Universidad Autónoma de Madrid).

Montero Málaga, Alicia Inés (2017b), “La implantación de la alta nobleza en Burgos (1476-1516): una aproximación a través de los linajes de Rojas, Manrique, Sarmiento y Velasco", Edad Media: Revista de Historia, 19, pp. 148-1483.

Montero Málaga, Alicia Inés (2017c), "Los nobles en la ciudad: Una aproximación a las relaciones ciudad-nobleza en la historiografía castellana de los siglos XX y XXI", en Jara Fuente, José Antonio (coord.), Discurso político y relaciones de poder: Ciudad, nobleza y monarquía en la Baja Edad Media, Madrid: Dykinson, pp. 21-88.

Moreno Ollero, Antonio (2014), Los dominios señoriales de la Casa de Velasco en la Baja Edad Media, Autoeditado.

Muñoz Gómez, Víctor (2016), Corona, señoríos y redes clientelares en la Castilla bajomedieval (ss. XIV-XV). El estado señorial y la casa de Fernando de Antequera y Leonor de Alburquerque, Infantes de Castilla y Reyes de Aragón (1374-1435), Valladolid, (tesis doctoral leída en la Universidad de ValladolidInstituto Universitario de Historia Simancas).

Muñoz Jiménez, José (2000), “Los Castillos del Condestable: fortalezas de la Casa de Velasco en el norte de España (1315-1522)", en Castillos de España: publicación de la Asociación Española de Amigos de los Castillos, 117, pp. 17-30.

Muñoz Jiménez, José (2011) "Señoríos, reparto territorial y fortificaciones en Cantabria durante la Baja Edad Media", en Castillos de España: publicación de la Asociación Española de Amigos de los Castillos, 161-163, pp. 79-92.

Ortega Cera, Ágatha (2010), "Arrendar el dinero del rey. Fraude y estrategias financieras en el Estrado de las Rentas en la Castilla del siglo XV", Anuario de Estudios Medievales, 40, pp. 201-227.

Ortega Cervigón, José Ignacio (2003), "El intrusismo nobiliario en los concejos castellanos: el oficio de guarda mayor de Cuenca durante el siglo XV", en Jiménez Alcázar, Juan Francisco; Ortuño Molina, Jorge; Eiroa Rodríguez, Jorge Alejandro (eds.), Actas I Simposio de Jóvenes Medievalistas Lorca 2002, Murcia: Universidad de Murcia, pp. 147-178.

Ortega Cervigón, José Ignacio (2011), "Ciudad, nobleza y frontera: el oficio concejil de guarda mayor en Cuenca y Huete durante el siglo XV", en Solórzano Telechea, Jesús Ángel; Arízaga Bolumburu, Beatriz (eds.), La gobernanza de 
la ciudad europea en la Edad Media, Logroño: Instituto de Estudios Riojanos, pp. 227-245.

Ortega Cervigón, José Ignacio (2006), “Títulos, señoríos y poder: los grandes estados señoriales en la Castilla centro-oriental", Quintanilla Raso, María Concepción (dir.), Títulos, grandes del reino y grandeza en la sociedad política. Fundamentos en la Castilla medieval, Madrid: Sílex, pp. 288-290.

Ortego Rico, Pablo (2012), "Estrategias financieras y especulación en torno al arrendamiento "por mayor" de rentas regias ordinarias en Castilla: aproximación al caso de Castilla La Nueva (1462-1504), en Bonachía Hernando, Juan Antonio; Carvajal de la Vega, David (coords.), Los negocios del hombre: comercio y rentas en Castilla, siglos XV y XVI, Valladolid: Castilla Ediciones, 2012, pp. 235-260.

Ortego Rico, Pablo (2015a), Poder financiero y gestión tributaria en Castilla: los agentes fiscales en Toledo y su reino (1429-1504), Madrid: Instituto de Estudios Fiscales.

Ortego Rico, Pablo (2015b), Poder financiero y gestión tributaria en Castilla: los agentes fiscales en Toledo y su reino (1429-1504), Apéndices, Madrid: Instituto de Estudios Fiscales.

Ortego Rico, Pablo (2018), “Los negocios de Rabí Yuçe Melamed/Luis Núñez Coronel: redes cooperativas, intermediación y gestión fiscal en el entorno de un operador judeoconverso a fines de la Edad Media en Castilla", e-Humanista, 6, pp. 42-65.

Palencia Herrejón, Juan Ramón (1995), Los Ayala de Toledo: desarrollo e instrumentos de poder de un linaje nobiliario en el siglo $X V$, Toledo: Diputación de Toledo.

Pardos Martínez, Julio (1982), "La renta de la alcabala vieja, portazgo y barra del concejo de Burgos durante el siglo XV (1429-1502), en VV.AA. Historia de la Hacienda Española (épocas antigua y medieval): Homenaje al profesor García de Valdeavellano, Madrid: Instituto de Estudios Fiscales, pp. 609-677.

Paulino Montero, Elena (2013), "Patrocino arquitectónico y política territorial en la Castilla bajomedieval: el caso de los Fernández de Velasco", Mínguez Cornelles, Víctor (coord.), Las Artes y la arquitectura del poder, Castellón de la Plana: Universitat Jaume I, pp. 1165-1184.

Paulino Montero, Elena (2015), El patrocinio arquitectónico de los Velasco (13131512). Construcción y contexto de un linaje en la Corona de Castilla, Madrid, (tesis doctoral leída en la Universidad Complutense de Madrid).

Pereyra Alza, Osvaldo (2014), El señorío de los Condestables de Castilla en el norte de España. Dominio, Patronazgo y Comunidades, Santander (tesis doctoral leída en la Universidad de Cantabria).

Pérez Bustamante, Rogelio (1983), "Un cuaderno de los diezmos de la mar de Galicia y Asturias 1451-1465", Boletín de la Real Academia de la Historia, CLXXX, pp. 355-375.

Porres Fernández, César Alonso (2009), El Buen Conde de Haro, Medina de Pomar: Asociación Amigos de Medina de Pomar. 
Quintanilla Raso, María Concepción (1979) Nobleza y señoríos en el reino de Córdoba: la Casa de Aguilar (siglos XIV y XV), Córdoba: Monte de Piedad y Caja de Ahorros.

Quintanilla Raso, María Concepción (1982), "Haciendas señoriales nobiliarias en el reno de Castilla a fines de la Edad Media”, en Historia de la Hacienda Española. Épocas antigua y medieval, Madrid: Ministerio de Hacienda-Instituto de Estudios Fiscales, pp. 767-798.

Quintanilla Raso, María Concepción (1982), "Estructuras sociales y familiares y el papel político de la nobleza cordobesa (siglos XIV-XV)", En la España medieval, 3, pp. 331-352.

Quintanilla Raso, María Concepción (1984), "Nobleza y señoríos en Castilla durante la Baja Edad Media. Aportaciones de la historiografía reciente", Anuario de Estudios Medievales, 14, pp. 613-639.

Quintanilla Raso, María Concepción (1987), "El dominio de las ciudades por la nobleza. El caso de Córdoba en la segunda mitad del siglo XV", En la España Medieval, 1, pp. 109-124.

Quintanilla Raso, María Concepción (1991), "Estructura y función de los bandos nobiliarios en Córdoba a fines de la Edad Media", en VV.AA Bandos y querellas dinásticas en España al final de la Edad Media. Actas del Coloquio celebrado en la Biblioteca Española de París los días 15 y 16 de mayo de 1987, Madrid: Ministerio de Asuntos Exteriores, pp. 157-176.

Quintanilla Raso, María Concepción (1995), "Marcos y formas de proyección de la nobleza conquense en su entorno urbano y territorial", en VV.AA. Congreso Internacional El tratado de Tordesillas y su época, Setúbal 2 de junio, Salamanca 3-4 de junio, Tordesillas, 5, 6 y 7 de junio de 1994, Madrid: Sociedad Quinto Centenario del Tratado de Tordesillas, vol. I, pp. 131-154.

Quintanilla Raso, María Concepción (1999), "La renovación nobiliaria en la Castilla bajomedieval. Entre el debate y la propuesta", en La nobleza peninsular en la Edad Media. VI Congreso de estudios medievales, León: Fundación Sánchez Albornoz, pp. 55-296.

Quintanilla Raso, María Concepción (2004) “Principios y estrategias de la cultura nobiliaria. Redes de solidaridad, clientelismo y facciones en la Córdoba de fines del Medievo", en VV.AA. Córdoba, el Gran Capitán y su época, Córdoba, Real Academia de Córdoba, pp. 47-74.

Quintanilla Raso, María Concepción (2006), (dir.), Títulos, grandes del reino y grandeza en la sociedad política. Fundamentos en la Castilla medieval, Madrid: Sílex.

Rubio Martínez, Amparo (2008), “La recaudación de tributos ordinarios por la mesa arzobispal compostelana en la tierra de Santiago: alcabalas, diezmos de la mar y alfolíes", Cuadernos de Estudios Gallegos, 121, pp. 197-233.

Rucquoi, Adeline (1982), "La enajenación de las rentas reales: el caso de Valladolid en los siglos XIII a XV", en Historia de la Hacienda Española. Épocas antigua y medieval, Madrid: Ministerio de Hacienda-Instituto de Estudios Fiscales, pp. 799-822. 
Salas Almela, Luis (2016), "Poder señorial, espacio fiscal y comercio: los diezmos de la mar, las rutas comerciales burgalesas y la casa de Velasco (1469-1559). Ensayo de interpretación de un proceso secular", Tiempos Modernos, 33, pp. 399-418.

Sánchez Saus, Rafael (2005), La nobleza andaluza en la Edad Media, Granada: Universidad de Granada.

Sebastián Moreno, Javier (2013), "Las relaciones burgalesas en la red urbana castellana. El caso empírico de Salinas de Añana", Estudios Medievales Hispánicos, 2, pp. 277-296.

Sebastián Moreno, Javier (2017a), La ciudad medieval como capital regional: Burgos (siglo $X V$ ), Madrid, (tesis doctoral leída en la Universidad Autónoma de Madrid).

Sebastián Moreno, Javier (2017b), La ciudad medieval como capital regional. Burgos en el siglo XV, Madrid: Ediciones Universidad Autónoma de Madrid.

Sebastían Moreno, Javier (2017c), "Las regiones de abastecimiento de la ciudad de Burgos en el siglo XV y el papel de la nobleza en el suministro urbano", en Jara Fuente, José Antonio (coord.), Discurso político y relaciones de poder: Ciudad, nobleza y monarquía en la Baja Edad Media, Madrid: Dykinson, pp. 477-512.

Solórzano Telechea, Jesús (2002), Santander en la Edad Media. Patrimonio, parentesco y poder, Santander: Universidad de Cantabria-Ayuntamiento de Torrelavega.

Suárez Fernández, Luis (2002), Enrique IV de Castilla: la difamación como arma política, Barcelona: Ariel.

Suárez Fernández, Luis (2003), Nobleza y Monarquía: entendimiento y rivalidad. El proceso de construcción de la Corona española, Madrid: La Esfera de los Libros.

Truchuelo García, Susana (2004), Gipuzkoa y el poder real en la Alta Edad Moderna, San Sebastián: Diputación Foral de Gipuzkoa.

Vítores Casado, Imanol (2001), “Compañías vascas en torno al arrendamiento y recaudación de la renta de los diezmos de la mar en Castilla a fines de la Edad Media", en Carvajal de la Vega, David; Añíbarro Rodríguez, Javier; Vítores Casado, Imanol (coords.), Redes sociales y económicas en el mundo bajomedieval, Valladolid: Castilla Ediciones, pp. 241-263.

VV. AA (1999), La nobleza peninsular en la Edad Media. VI Congreso de estudios medievales, León: Fundación Sánchez Albornoz.

Yun Casalilla, Bartolomé (1991), “Aristocracia, corona y oligarquías urbanas en Castilla ante el problema fiscal. 1450-1600”, en Historia de la Hacienda en España (siglos XVI-XX). Homenaje a Don Felipe Ruíz Marín, Madrid: Ministerio de Hacienda, pp. 25-41.

Yun Casalilla, Bartolomé (2002), La gestión del poder. Corona y economías aristocráticas en Castilla (siglos XVI-XVIII), Madrid: Akal. 